\title{
Reciprocal Regulation of Endocytosis and Metabolism
}

\author{
Costin N. Antonescuํㅜ, Timothy E. McGraw ${ }^{2}$, and Amira Klip ${ }^{3}$ \\ ${ }^{1}$ Department of Chemistry and Biology, Ryerson University, Toronto, Ontario M5B 2K3, Canada \\ ${ }^{2}$ Department of Biochemistry, Weill Medical College of Cornell University, New York, New York 10065 \\ ${ }^{3}$ Program in Cell Biology, The Hospital for Sick Children, Toronto, Ontario M5G 1X8, Canada \\ Correspondence: temcgraw@med.cornell.edu; amira@sickkids.ca
}

The cellular uptake of many nutrients and micronutrients governs both their cellular availability and their systemic homeostasis. The cellular rate of nutrient or ion uptake (e.g., glucose, $\mathrm{Fe}^{3+}, \mathrm{K}^{+}$) or efflux (e.g., $\mathrm{Na}^{+}$) is governed by a complement of membrane transporters and receptors that show dynamic localization at both the plasma membrane and defined intracellular membrane compartments. Regulation of the rate and mechanism of endocytosis controls the amounts of these proteins on the cell surface, which in many cases determines nutrient uptake or secretion. Moreover, the metabolic action of diverse hormones is initiated upon binding to surface receptors that then undergo regulated endocytosis and show distinct signaling patterns once internalized. Here, we examine how the endocytosis of nutrient transporters and carriers as well as signaling receptors governs cellular metabolism and thereby systemic (whole-body) metabolite homeostasis.

Interactions between the cell and its environment obligatorily involve events at the plasma membrane. Cell-surface proteins mediate nutrient uptake, product release, and the sensing of environmental changes, including signals from other cells. Appropriate sensing and response to extracellular cues is essential for the individual cell's survival and for the coordinated cellular behavior in multicellular organisms. Accordingly, maintenance and dynamics of membrane proteins are fundamental mechanisms of cellular homeostasis and survival.

Most plasma membrane proteins are in defined equilibria with intracellular endosomal compartments, such that the amount of a given protein at the plasma membrane is determined by the balance of its endocytosis and its recycling back to the cell surface from endosomes and other intracellular compartments (Fig. 1). Changes in the kinetics of membrane protein traffic acutely affect the levels of individual proteins at the cell surface and thereby impact how cells intake nutrients, sense the environment, and respond to external cues.

Selective molecular mechanisms trigger traffic of plasma membrane proteins through endomembranes. Among them, ubiquitination and phosphorylation stand out as they can directly target the cargo proteins. Ubiquitination is the covalent attachment of the 76-amino acid polypeptide ubiquitin to the $\varepsilon$-amino group of specific lysine residues (reviewed by Miranda

Editors: Sandra L. Schmid, Alexander Sorkin, and Marino Zerial

Additional Perspectives on Endocytosis available at www.cshperspectives.org

Copyright (C) 2014 Cold Spring Harbor Laboratory Press; all rights reserved; doi: 10.1101/cshperspect.a016964

Cite this article as Cold Spring Harb Perspect Biol 2014;6:a016964 
C.N. Antonescu et al.

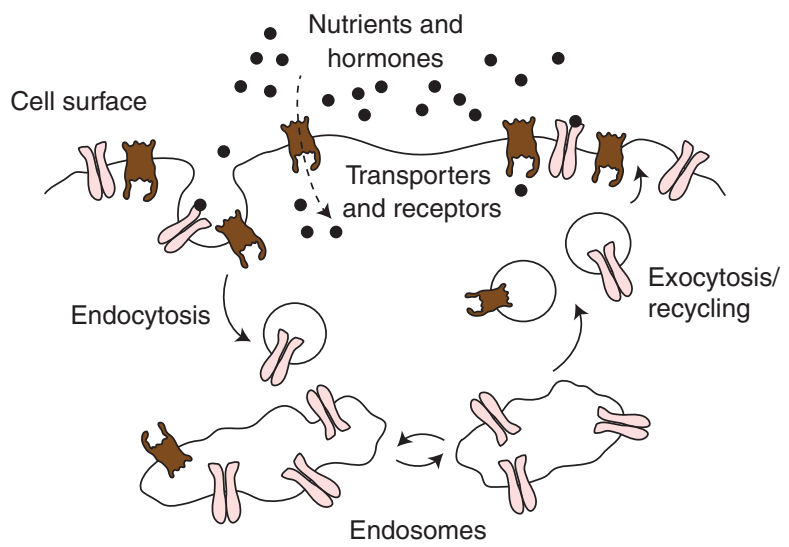

Figure 1. Dynamic regulation of the cell-surface content of membrane proteins. Integral membrane proteins found at the cell surface are dynamically localized to the plasma membrane. The amount of any of these proteins at the cell surface is the result of the balance of exocytosis or recycling of vesicles containing that protein from intracellular membrane compartments and the endocytosis of the protein from the cell surface. Regulation of either the rate of exocytosis or endocytosis results in alteration of the cell-surface content of a given protein.

and Sorkin 2007; and see also Piper et al. 2014). Ubiquitination of cell-surface proteins is the principal mechanism of control of endocytosis in yeast (MacGurn et al. 2012), whereas in mammals, additional molecular mechanisms regulate the endocytosis of cell-surface proteins, including alterations in conformation that impact interaction with other proteins, and as mentioned, phosphorylation. Each of these modifications can either enhance or reduce the rates internalization, recycling, or degradation of specific proteins, highlighting the complexity of the regulation of endomembrane traffic. The intricate mechanisms that underlie the reciprocal regulation of endocytosis and metabolism are beginning to be understood. Here we discuss the endocytosis mechanisms in the regulation of cellular intake or efflux of iron, cholesterol, $\mathrm{Na}^{+}$, and glucose, and in the regulation of receptor signaling relevant to metabolism.

\section{ENDOCYTOSIS IS REQUIRED FOR THE UPTAKE OF CIRCULATING NUTRIENT CARRIERS}

Regulation of Iron Homeostasis by Transferrin Internalization

Ferric iron $\left(\mathrm{Fe}^{3+}\right)$ is an essential nutrient that is carried in the blood by transferrin (Tf), a high- affinity iron chelating glycoprotein made by the liver (Gkouvatsos et al. 2012). Endocytosis of diferric Tf is the principal mechanism for cellular $\mathrm{Fe}^{3+}$ uptake. Transferrin receptor 1 (TfR1), a homodimeric type II transmembrane protein that binds Tf- $-\mathrm{Fe}_{2}{ }^{3+}$ with nanomolar affinity, is the primary receptor mediating cellular uptake (Fig. 2). The Tf- $\mathrm{Fe}_{2}{ }^{3+}$ :TfR 1 complex is internalized by clathrin-mediated endocytosis (CME) (Dautry-Varsat et al. 1983; Klausner et al. 1983). At the acidic luminal $\mathrm{pH}$ of endosomes ( $\mathrm{pH}$ 5.5-6.0), $\mathrm{Fe}^{3+}$ is released from Tf, reduced, and transported to the cytosol. Apo-Tf (ironfree) has high affinity for TfR 1 at acidic $\mathrm{pH}$ and therefore remains bound to TfR1 in endosomes. The Apo-Tf:TfR 1 complex returns to the plasma membrane through mildly acidic, endocytic recycling compartments. Apo-Tf has an approximate $\sim 500$-fold lower affinity for TfR 1 at neutral $\mathrm{pH}$ and it is therefore released from TfR 1 following the fusion of recycling vesicles with the plasma membrane (where it is exposed to extracellular milieu of $\mathrm{pH}$ 7.4). The released apo-Tf is free to bind $\mathrm{Fe}^{3+}$ in the blood and mediate additional $\mathrm{Fe}^{3+}$ delivery upon binding to TfR1.

TfR 1 constitutively cycles between the plasma membrane and endosomes (Watts 1985; Gironès and Davis 1989). Internalization of TfR1 is mediated by a cytoplasmic YTRF-based motif 


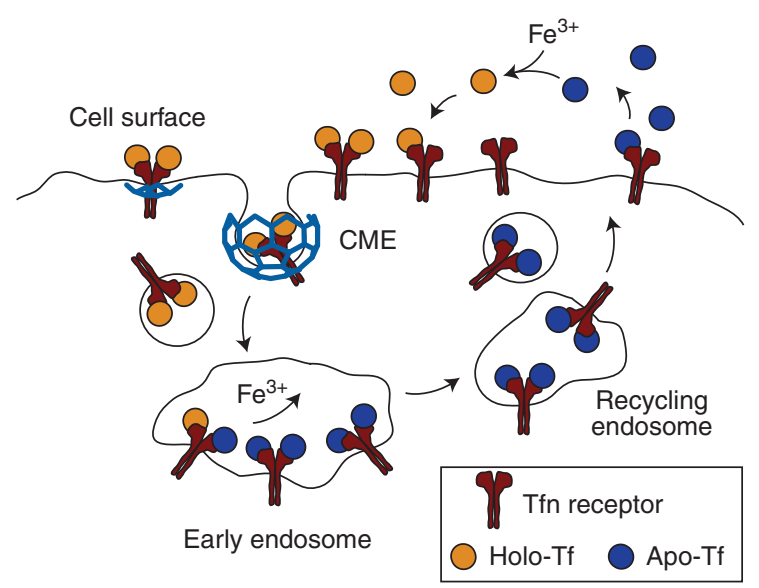

Figure 2. The uptake of iron through endocytosis and recycling of transferrin. Iron-bound transferrin (holo-Tf) binds to the transferrin receptor (TfR) at the cell surface. TfR constitutively internalizes via clathrin-mediated endocytosis. Arrival of the Tf/TfR complex to the acidic environment of endosomes results in dissociation of iron from Tf. This is followed by recycling of the apo-Tf/TfR complex to the cell surface, where apo-Tf dissociates from TfR. The iron is thereby retained intracellularly, and Tf and TfR are able to participate in additional rounds of iron uptake.

associating with the $\mu$-subunit of the AP2 clathrin adaptin complex (Jing et al. 1990; McGraw and Maxfield 1990; Ohno et al. 1995; Owen and Evans 1998). Mutations in YTRF reduce the internalization rate constant of the TfR 1 and correspondingly reduce the rate of $\mathrm{Fe}^{3+}$ intracellular accumulation, revealing that internalization of the TfR 1 is rate limiting for $\mathrm{Fe}^{3+}$ uptake (McGraw and Maxfield 1990; Pytowski et al. 1995).

Although both constitutive endocytosis and recycling of TfR1 are key elements controlling cellular $\mathrm{Fe}^{3+}$ accumulation by maintaining the appropriate steady-state level of TfR 1 at the plasma membrane, the regulation of TfR 1 traffic (endocytosis and/or recycling) is not a major mode for the modulation of cellular of $\mathrm{Fe}^{3+}$ accumulation. Rather, regulation of iron accumulation is controlled at the level of TfR1 mRNA stability (Rouault 2006). In low $\mathrm{Fe}^{3+}$ conditions there is increased TfR 1 mRNA stability and elevated total TfR1 protein that brings about a steady-state increase of TfR 1 at the plasma membrane and augmented capacity for Tf uptake. Conversely, with elevated $\mathrm{Fe}^{3+}$ there is reduced TfR1 translation. In addition, increased $\mathrm{Fe}^{3+}$ results in TfR1 ubiquitination, which di- rects the receptor to degradation in lysosomes (Tachiyama et al. 2011). Together, these mechanisms control less $\mathrm{Fe}^{3+}$ accumulation upon elevated cellular $\mathrm{Fe}^{3+}$.

Whole body iron homeostasis is achieved by the balance of TfR1-mediated uptake from duodenal enterocytes (dietary iron) and macrophages (iron recycled from erythrocytes) to the plasma via the ferroportin (FPN)-dependent iron transport (Donovan et al. 2005). The amount of FPN at the surface of these cells determines the rate of iron export to plasma. Hepcidin, a liver-produced, 27-amino acid hormone, controls iron transport from enterocytes and macrophages into the plasma by inhibiting FPN. Hepcidin binds FPN inducing its ubiquitylation-dependent endocytosis (Nemeth et al. 2004; Qiao et al. 2012). Internalized FPN is targeted to lysosomes for degradation. Although the molecular details of the ubiquitin-based FPN internalization and down-regulation have not been fully elucidated, it is clear that hepcidin regulation of FPN endocytosis is essential for iron homeostasis, because mutations that affect hepcidin-FPN binding or FPN ubiquitylation cause iron overload diseases in animal models and humans (De Gobbi et al. 2002). Thus, reg- 
C.N. Antonescu et al.

ulation of FPN endocytosis is a physiologically important example of the acute regulation of a nutrient carrier by endocytosis.

Low-Density Lipoprotein Receptor Endocytosis Facilitates Cellular Cholesterol Uptake

Cellular cholesterol uptake occurs through binding of low-density lipoprotein (LDL) particles by the LDL receptor (LDLR), followed by receptor endocytosis. LDLR binds apo-B100, which is present in a single copy within each LDL particle (Jeon and Blacklow 2005; Goldstein and Brown 2009). Upon internalization, the lower endosomal $\mathrm{pH}$ causes dissociation of LDL from its receptor. LDLR recycles back to the cell surface (Brown et al. 1983), whereas LDL continues to lysosomes, where cholesterol is released and rerouted. Cholesterol uptake by this mechanism also suppresses endogenous cholesterol biosynthesis.

LDLR internalization occurs via CME (Jeon and Blacklow 2005; Goldstein and Brown 2009). Early studies identified aromatic-based endocytic sorting motifs on LDLR (Davis et al. 1987) and the ${ }^{802}$ FDNPVY $^{807}$ sequence was later shown to act as a recognition motif for the CME adaptor protein ARH (Traub 2003). Interestingly, LDLR endocytosis by CME requires the endocytic adaptor proteins ARH or Dab2, which are dispensable for internalization of other CME cargo such as TfR1 (He et al. 2002; Maurer and Cooper 2006).

LDL particles are $\sim 22 \mathrm{~nm}$ in diameter, making each LDL-LDLR complex significantly larger than most CME cargo. Expression of a chimeric protein harboring the cytoplasmic region of LDLR results in ARH- and Dab2-dependent changes in the size of clathrin-coated pits, even in the absence of LDL (Mettlen et al. 2010). This indicates that incorporation of LDLR-ARH/ Dab2 complexes into endocytic structures may "customize" CME to accommodate these larger cargoes.

LDLR also contributes to the internalization of other lipoproteins, including very-low-density lipoproteins (VLDL). This raises the question of how the internalization of a single receptor may regulate the unique homeostasis of distinct lipoproteins. Interestingly, LDL uptake but not that of VLDL by LDLR involves ARH S-nitrosylation at C199 and C286 (Zhao et al. 2013), required for ARH interaction with AP2. This suggests a mechanism by which LDLR-dependent cellular internalization of LDL can be separately regulated from that of VLDL, thereby defining a mechanism by which the systemic metabolism of these different lipoproteins can be distinctly regulated.

Strikingly, of the nearly 1000 mutations in LDLR linked to genetic hypercholesterolemia (Leigh et al. 2008), several impair LDLR internalization but not LDL binding (Hobbs et al. 1990). In particular, one of the first monogenetic mutations identified in LDLR leading to hypercholesterolemia was Y807C; thus mutated LDLR shows markedly lower recruitment of LDLR to clathrin-coated pits and virtually ablated LDLR endocytosis (Davis et al. 1986). Moreover, mutations in ARH that impair LDLR internalization also lead to autosomalrecessive hypercholesterolemia (Soutar et al. 2003). Collectively, these studies reveal a critical contribution of LDLR endocytosis to systemic cholesterol homeostasis (Bonfleur et al. 2010).

\section{ENDOCYTOSIS LIMITS GLUCOSE UPTAKE AND $\mathrm{Na}^{+}$EFFLUX THROUGH MEMBRANE TRANSPORTERS}

In contrast to the cellular internalization of iron and cholesterol carriers described above, other nutrients and micronutrients are taken up directly through membrane-bound transporters straight into the cytosol. Efflux also occurs directly from the cytosol to the extracellular milieu across membrane transporters. The rate of nutrient or micronutrient uptake/efflux is largely determined by the permanence of their cognate transporters at the cell surface, which is fundamentally controlled by the balance of their endocytosis and recycling.

GLUT Endocytosis Limits the Rate of Cellular Glucose Uptake

A family of facilitative glucose transporters, GLUTs, is responsible for the transport of glu- 
cose from the blood into cells. The 14 different GLUTs vary in their tissue expression and intrinsic transport parameters such as turnover number (Mueckler and Thorens 2013). Here we discuss the contribution of endocytosis of two of them, GLUT1 and GLUT4, to the regulation of glucose transport. Notably, each of these transporters cycles differentially within the cell, and indeed their rates of endocytosis differ substantially: Whereas GLUT4 is rapidly removed from the cell surface to be stored in still poorly described but highly dynamic storage vesicles, GLUT1 has a longer permanence at the cell surface. Recent studies have discovered that the endocytosis of each of these transporters is exquisitely regulated. Brief examples are presented next.

\section{GLUT1}

GLUT1, the most widely expressed GLUT isoform, mediates glucose uptake into most cell types. Glucose uptake through GLUT1 is regulated by changes in the individual transporter efficiency ("transport activity," such as by intracellular ATP levels) (Blodgett et al. 2007) and in the number of transporters at the plasma membrane. Here we focus on the latter mechanism as a means to regulate glucose flux.

In hematopoietic cells, cytokines (e.g., interleukin 3) promote glucose uptake by raising the amount of GLUT1 at the plasma membrane (Kan et al. 1994; Rathmell et al. 2001). This increase is achieved via cytokine-induced inhibition of GLUT1 internalization from the membrane and stimulation of GLUT1 translocation from intracellular compartments to the membrane (Fig. 3) (Wieman et al. 2007; Wofford et al. 2008). Upon cytokine withdrawal, GLUT1 internalization is accelerated and recycling to the plasma membrane inhibited, resulting in an acute, net reduction of GLUT1 at the plasma membrane and a corresponding drop in glucose

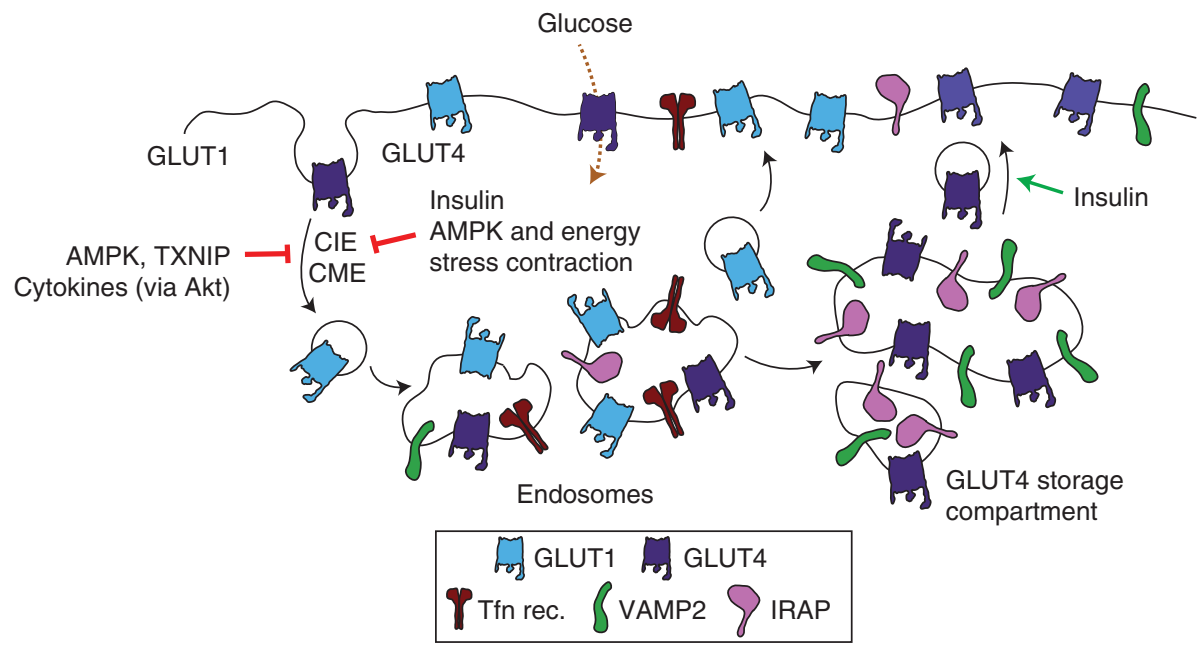

Figure 3. Control of glucose uptake by regulation of GLUT1 and GLUT4 endocytosis. Glucose transport from the extracellular milieu to the cytoplasm occurs selectively by glucose transporters (GLUTs) present at the cell surface. GLUT4 endocytosis occurs through both clathrin-mediated (CME) as well as clathrin-independent (CIE) endocytosis. The cell-surface content, and hence the rate of glucose uptake by GLUT1 and GLUT4, is regulated by alterations in the endocytosis of these glucose transporters, as well as the rates of recycling. Moreover, GLUT1 and GLUT4 undergo distinct intracellular sorting, with $\sim 50 \%$ of GLUT4 residing in a specialized storage compartment. Shown are some of the stimuli and intracellular signals that reduce the endocytosis of GLUT1 and GLUT4 or increase transporter recycling and thereby increase the rate of cellular glucose uptake. Also shown are the insulin-responsive aminopeptidase (IRAP) and VAMP2, which are enriched in the GLUT4 storage compartment and the transferrin receptor (Tfn rec.), which is not, and is instead found largely in recycling endosomes. 
C.N. Antonescu et al.

transport. The molecular mechanism for cytokine-induced changes in GLUT1 traffic has not been fully described. It is known that it occurs downstream from the Akt kinase, because enforced expression of constitutively active Akt prevents enhanced GLUT1 internalization and reduced recycling upon growth factor withdrawal (Wieman et al. 2007).

In a different physiological context, cellular energy deprivation enacts an emergency response that increases glucose uptake. This is in part mediated by an increase in surface GLUT1, which is in the short run mediated by inhibition of its constitutive endocytosis, and in the long run by enhanced GLUT1 synthesis. The elements participating in the acute response were recently found to involve the arrestin-domaincontaining protein (ARRDC), thioredoxin-interacting protein (TXNIP). TXNIP expression correlates with glucose transport and its knockdown in adipose and muscle cells lowered glucose uptake (Parikh et al. 2007). TXNIP affects GLUT1 traffic (Wu et al. 2013), by forming a complex that promotes its internalized through clathrin-coated pits. Although ARRDCs are involved in the ubiquitination of membrane proteins (MacGurn et al. 2012), ubiquitination of GLUT1 has not been reported, and it is not known if TXNIP controls GLUT1 endocytosis by ubiquitination of another protein. The TXNIP-induced drop in surface GLUT1 reduces glucose transport.

TXNIP transcription is under the regulation of a number of different glucose-sensing transcription complexes, CHREBP-Mlx and MondoA-Mlx, such that TXNIP mRNA levels increase with increasing glucose uptake. Because TXNIP has an inhibitory effect on glucose uptake, the glucose-stimulated increased TXNIP mRNA provides a negative-feedback loop for GLUT1-mediated glucose uptake. In addition, TXNIP phosphorylation by AMP-dependent protein kinase (AMPK) promotes its degradation (Wu et al. 2013). AMPK is activated when the AMP/ATP ratio increases, therefore AMPKinduced degradation of TXNIP will result in elevated plasma membrane GLUT1 as a consequence of reduced internalization, and a corresponding increase of glucose uptake and ATP generation ensue. Further, TXNIP also reduces GLUT1 transcription, contributing to the longterm reduction in glucose uptake.

\section{GLUT4}

GLUT4 expression is mostly limited to muscle and adipose cells (Mueckler and Thorens 2013) and is responsible for most of the glucose retrieval from blood following a meal. In the fasted state (between meals) glucose transport into adipose and muscle cells is low because $90 \%-$ 95\% of GLUT4 is sequestered intracellularly (Li et al. 2001; Huang and Czech 2007). Insulin, which increases in the blood upon feeding, stimulates a rapid (within minutes) redistribution of GLUT4 from intracellular compartments to the plasma membrane, causing a concomitant surge in glucose transport into these tissues (Foley et al. 2011; Rowland et al. 2011). The elevated rate of glucose transport thus achieved is behind the return of blood glucose levels back to prefeeding levels within $1-2 \mathrm{~h}$ (Ferrannini et al. 1985). The redistribution of GLUT4 to the plasma membrane is reversible. When blood insulin levels wane, GLUT4 redistributes back from the plasma membrane to intracellular compartments. Unlike intracellular GLUT1, which transits only through recycling endosomes, GLUT4 is unique in its sorting out of recycling endosomes into the TGN and a specific "GLUT4 storage" compartment. The nature of this compartment is highly debated, but it is apparent that it excludes certain proteins such as GLUT1 and most of the TfR1, whereas it is enriched in proteins such as VAMP2 and IRAP (Fig. 3) (Jedrychowski et al. 2010; Foley et al. 2011; Stöckli et al. 2011; Leto and Saltiel 2012). Most studies agree that the GLUT4 storage compartment is distinct from the TGN although it contains proteins such as Syntaxin- 6 and -16 , and these may contribute to its sorting or functionality. Sorting to this selective compartment, unique to fat and muscle cells, may prevent GLUT4 from degradation and may account for its strikingly long halflife (nearly $48 \mathrm{~h}$ ). The localization of this unique compartment is also poorly defined, in part owing to spatial constraints in adipose and mature 
muscle cells, and to its dynamic nature. However, there is general agreement that GLUT4 sequestration is essential for its appropriate response to insulin and hence defining the full complement of signals dictating the dynamic retention of GLUT4 in intracellular stores is of utmost physiological importance.

\section{GLUT4 Internalization in the Basal State}

GLUT4 is a very long-lived protein; hence, each molecule can undergo numerous cycles of internalization and recycling. The pronounced intracellular GLUT4 sequestration in unstimulated fat and muscle cells is owing to its rapid internalization and slow recycling. GLUT4 contains sequences that determine its endocytosis and intracellular sorting. When ectopically expressed in fibroblast-like cells, both the phenylalanine-based motif FQQI on the GLUT4 amino-terminal cytoplasmic domain and a dileucine motif on its carboxy-terminal cytoplasmic domain function as internalization motifs (Corvera et al. 1994; Garippa et al. 1994, 1996; Verhey et al. 1995). These motifs suffice to promote internalization when transferred to other proteins, and belong to the two major families of membrane protein sorting signals: aromaticbased motifs and dileucine-based motifs (Seaman 2008; see also Traub and Bonifacino 2013). However, the aromatic-based motif on GLUT4 has a phenylalanine instead of the more common tyrosine. Substitution of the endogenous phenylalanine for tyrosine in the GLUT4 motif promotes faster $(2 \times)$ internalization of the transporter (Garippa et al. 1996; Blot and McGraw 2006). Similarly phenylalanine-based motifs on other proteins promote a slower internalization compared with tyrosine-based motifs (e.g., McGraw and Maxfield 1990). The behavior of GLUT4 in fibroblast-like cells is consistent with its internalization by a clathrin/AP2-dependent pathway, although the mechanism of internalization of ectopically expressed GLUT4 endocytosis in these cells has not been rigorously investigated. In contrast, more recent studies in 3T3-L1 adipocytes reveal that, in the basal state, GLUT4 is internalized by a cholesterol-dependent, nystatin-sensitive path- way that is independent of AP2 or any of the known GLUT4 membrane protein traffic motifs (Blot and McGraw 2006). In unstimulated L6 muscle cells, GLUT4 internalizes via both a clathrin-dependent and a cholesterol and dynamin-dependent but caveolin-independent mechanism (Antonescu et al. 2008a, 2009). Kinetically, GLUT4 endocytosis differs from that of the TfR 1 or the receptor for $\alpha 2$-macroglobulin (Habtemichael et al. 2011), markers of CME and non-CME, noncaveolar internalization.

\section{GLUT4 Internalization in Response to Insulin}

In muscle and fat cells the predominant effect of insulin is enhanced recycling (i.e., re-exocytosis) of GLUT4 to the plasma membrane (Li et al. 2001; Karylowski et al. 2004; Martin et al. 2006; Blodgett et al. 2007; Antonescu et al. 2008b, 2008a; Ishikura et al. 2010), and this is also the case in skeletal muscle (Karlsson et al. 2009). In adipocytes, insulin also slows down GLUT4 internalization (Fig. 3) (Czech and Buxton 1993; Blot and McGraw 2006), but this does not occur in either cardiomyocytes (Yang and Holman 2005) or L6 muscle cells (Li et al. 2001; Antonescu et al. 2008a, 2009) (although a report to the contrary exists [Fazakerley et al. 2010]). Once internalized, insulin enhances the rate of GLUT4 transit through recycling endosomes (Foster et al. 2001). Although the magnitude of the effect of insulin on recycling is greater than on internalization, both changes contribute significantly to the net redistribution of GLUT4 to the plasma membrane. This may be one reason why the insulin-dependent net gain in surface GLUT4 - and its consequent glucose uptake-is larger in adipocytes than in muscle or heart cells. The molecular basis of insulininduced reduction in GLUT4 internalization in adipocytes is beginning to be understood. Under this stimulus, the FQQI motif functions as the main GLUT4 internalization motif, promoting uptake via an AP2-dependent mechanism (Blot and McGraw 2006). Thus, the data suggest that the GLUT4 internalization route varies between insulin-stimulated and -unstimulated adipocytes (respectively, AP2-depen- 
C.N. Antonescu et al.

dent and -independent). How this change in route is achieved is unknown. By comparison, GLUT4 internalizes through both clathrin-dependent and clathrin-independent routes in both basal and insulin-stimulated muscle cells, and insulin does not appear to change the proportion or rate of internalization of either route (Antonescu et al. 2008a, 2009). GLUT4 internalization appears to require the F-BAR-domain-containing protein CIP4, perhaps to cause membrane curvature for formation of endocytic vesicles (Hartig et al. 2009; Feng et al. 2010).

What is the significance of the different internalization routes? Although this is still an open question, one can make certain testable predictions: If the cholesterol-dependent route is faster than the FQQI-dependent one, the insulin-dependent shift to clathrin/AP2-mediated internalization through the FQQI motif in adipocytes might allow for longer permanence at the plasma membrane of each transporterto enact more rounds of glucose transportbefore being internalized. This would be facilitated by the slower internalization conferred to GLUT4 by the FAAI motif (compared with the canonical YQQI motif). The slower internalization would be compounded by the gain in transporters at the membrane resulting from increased recycling. In muscle, the clathrin-dependent pathway operating in the basal state might confer a slower internalization that could be advantageous for its physiological needs.

\section{GLUT4 Internalization in Response to Energy Demand}

Processes that increase energy demand require an adaptive increase in carbon source to sustain cellular viability (Cartee et al. 1991). This adaptive response in other cells is ascribed to GLUT1 (see above), but muscle largely depends on GLUT4 for influx of glucose. In contrast to insulin stimulation, energy status signaling leads to a marked slowdown of GLUT4 endocytosis in muscle cells. Metabolic stress resulting from treatment of cardiomyocytes with metformin or oligomycin (Yang and Holman 2005) or of L6 muscle cells with 2,4-dinitrophenol (DNP)
(Antonescu et al. 2008a) slows the rate of GLUT4 endocytosis (Fig. 3). DNP causes an initial and abrupt drop in cellular ATP with concomitant activation of AMPK; within minutes, intracellular ATP levels bounce back, coincident with the AMPK-dependent increase in cell surface GLUT4 elicited by DNP (Klip et al. 2009). Thus, AMPK reduces GLUT4 endocytosis to enhance GLUT4 permanence at the membrane. Indeed, activation of AMPK by treatment of L6 muscle cells with the AMPK-activator AICAR alone (Fazakerley et al. 2010) or AICAR in combination with exogenous activation of protein kinase C (Antonescu et al. 2008a) lowered the rate of GLUT4 endocytosis. Other examples of reduced GLUT4 endocytosis upon exposure of energy stressors include the response of adipocytes to dimethyl sulfoxide (Berenguer et al. 2011), rosiglitazone (Velebit et al. 2011), metformin (Yang and Holman 2006), and chronic insulin (Pryor et al. 2000).

In physiological conditions, muscle contraction vigorously uses ATP that must be replenished by glucose influx. Contraction increases surface GLUT4 levels in skeletal muscle (Douen et al. 1990; Goodyear et al. 1991) and this occurs through both AMPK- and $\mathrm{Ca}^{2+}$-dependent signals. Interestingly, in noncontracting muscle cells, a depolarization-induced influx of $\mathrm{Ca}^{2+}$ suffices to reduce GLUT4 internalization, and this response is independent of AMPK availability (Wijesekara et al. 2006). Moreover, a calcium ionophore, ionomycin, can slow down the rate of GLUT4 endocytosis and promote GLUT4 exocytosis, but only the latter effect is AMPK-dependent (Q Li, P Bilan, W Niu, et al., unpubl.). The exocytic increase in surface GLUT4 in exercised muscle is also AMPK dependent (Lauritzen et al. 2010). Intriguingly, the AICAR had only a minor effect on GLUT4 exocytosis in skeletal muscle (Karlsson et al. 2009), suggesting that AMPK may instead act on the endocytic step and/or that it may act in concert with other physiological signals to increase surface GLUT4 during muscle contraction. Hence, AMPK regulates GLUT4 endocytosis in conditions of energy demand (e.g., DNP treatment) and GLUT4 exocytosis in response to $\mathrm{Ca}^{2+}$-dependent signals. Collectively, these 
studies show that signals elicited by alterations in energy status and during skeletal muscle contraction converge to regulate the rates of GLUT4 endocytosis and exocytosis, thereby enhancing intake of energy-providing glucose.

\section{$\mathrm{Na} / \mathrm{K}$-ATPase Endocytosis Controls Multiple Metabolic Functions}

In all mammalian cells, an electrochemical gradient — creating a voltage difference that is typically negative with regards to the external milieu-ensures proper movement of ions and regulation of cell volume. At the core of the maintenance of this electrochemical $\mathrm{Na}^{+}$gradient lays the $\mathrm{Na}^{+} / \mathrm{K}^{+}$-ATPase or $\mathrm{Na}^{+} / \mathrm{K}^{+}$pump. By expending one ATP molecule per cycle of efflux of three intracellular $\mathrm{Na}^{+}$ions and influx of two extracellular $\mathrm{K}^{+}$ions, the pump ensures rapid riddance of any $\mathrm{Na}^{+}$ions that increase in the cytosol as a result of numerous $\mathrm{Na}^{+}$-dependent influx processes. Such preceding influx processes are key for lowering intracellular $\mathrm{Ca}^{2+}\left(\mathrm{Na}^{+} / \mathrm{Ca}^{2+}\right.$ exchange $), \mathrm{Na}^{+}$-coupled amino acid transport, $\mathrm{Na}^{+}$-coupled glucose uptake in epithelial cells, and for a diversity of $\mathrm{Na}^{+}, \mathrm{K}^{+}$ and $\mathrm{Cl}^{-}$transport processes. In fact, the $\mathrm{Na}^{+} /$ $\mathrm{K}^{+}$pump is the main, if not only, mechanism of $\mathrm{Na}^{+}$efflux from most cells. In parallel, the pump returns $\mathrm{K}^{+}$to cells that release or leak this ion in the course of their electrical activity, such as during action potentials in neurons, skeletal, smooth and heart muscles, and neuroendocrine cells. Another fundamental function of the pump is the translocation of $\mathrm{Na}^{+}$from one side of epithelia to the other, that along with obligatory anion movement generates the osmotic gradient that drives water absorption or resorption.

With this tall order, it is not surprising that the activity of the $\mathrm{Na}^{+} / \mathrm{K}^{+}$pump is rapidly and exquisitely regulated. This is achieved by changes in both the activity and the availability of the pump at the surface of the cell in question.

\section{Structural Properties of the $\mathrm{Na}^{+} / \mathrm{K}^{+}$Pump}

The pump consists of a heterodimer of one catalytic $\alpha$ subunit and one stabilizing, highly glycosylated $\beta$ subunit. The $110-\mathrm{kDa} \alpha$ subunit has 10 transmembrane segments, whereas the $31.5 \mathrm{kDa} \beta$ subunit crosses the membrane once. The $\alpha \beta$ heterodimer is the stable form, as changes in copy number of the $\alpha$ subunit require concomitant changes in the $\beta$ subunit to create functional units. Depending on the cell type, about 800,000 to 30 million pump copies are present at the cell surface at any given time. Abnormal changes in the copy number of pump units occur in several pathologies such as heart failure and hypertension associated with excessive renal $\mathrm{Na}^{+}$resorption. The functional pump involves one of four isoforms of the catalytic $\alpha$ subunit and one of any of the three isoforms of the stabilizing $\beta$ subunit. The gene transcription and translation control of each of these subunits is tissue specific and differentially regulated by diverse physiological conditions, as is the catalytic activity of the $\alpha$ subunit. On top of that, the regulation of pump availability at the cell membrane through exocytosis and endocytosis is a fundamental physiological control mechanism.

\section{Pump Regulation by Exocytosis}

The increase in pump surface exposure is best exemplified by the increase in surface $\alpha 2$ and $\beta 1$ subunits that occurs in skeletal muscle in response to insulin (Hundal et al. 1992; Ewart and Klip 1995; Benziane and Chibalin 2008). This rapid up-regulation of surface pump number occurs independently of biosynthetic changes and although typically ascribed to translocation to the membrane, the endocytic and exocytic arms of pump traffic in response to insulin have not been directly measured. A rapid increase in surface pump units is vital to manage the rapid uptake of dietary $\mathrm{K}^{+}$(along with the $\mathrm{Na}^{+}, \mathrm{K}^{+}, \mathrm{Cl}^{-}$cotransporter) and importantly handles the elimination of cytosolic $\mathrm{Na}^{+}$excess that results from $\mathrm{Na}^{+}$-coupled amino acid uptake and $\mathrm{Na}^{+} / \mathrm{H}^{+}$exchange promoted by the hormone. A similar up-regulation occurs in the contracting skeletal muscle fiber. In the central nervous system, the pump is up-regulated on demand to mediate $\mathrm{K}^{+}$reuptake and rids neurons of $\mathrm{Na}^{+}$gained during electrical activity. 
C.N. Antonescu et al.

\author{
$\mathrm{Na}^{+} / \mathrm{K}^{+}$-Pump Endocytosis Triggered \\ by $\mathrm{CO}_{2}$ and Hypoxia in the Lung
}

Changes in $\mathrm{CO}_{2}$ and $\mathrm{O}_{2}$ tension occur continuously in the lung, and when these changes are extreme, fluid movement needs to be regulated. This is enacted primarily through changes in the availability of the $\mathrm{Na}^{+} / \mathrm{K}^{+}$pump at the alveolar cell surface, as the pump is the driving force for ion-accompanying fluid movement (Bertorello and Sznajder 2005). Elevations in $\mathrm{CO}_{2}$ (hypercapnia) and reductions in $\mathrm{O}_{2}$ (hypoxia) demand an adaptive reduction in $\mathrm{Na}^{+}$ flux through the cells, and this is achieved by reducing the number of $\mathrm{Na}^{+} / \mathrm{K}^{+}$pumps at the cell surface, through their rapid endocytosis. In fact, the endocytosis of the pump in alveolar epithelial cells controls whole body $\mathrm{CO}_{2}$ clearance and alveolar fluid resorption. The reduction in pump units at the cell surface also curbs ATP utilization, given the high energetic demand imposed by pump activity (up to 30\% of the alveolar cell ATP). This reduction is beneficial in conditions of hypoxia. However, endocytosis of the pump can result in decreased alveolar fluid clearance.

The lung preferentially expresses the $\alpha 1$ and $\beta 1$ subunits. The endocytosis of pump subunits at the basolateral surface of primary and immortalized alveolar cells (e.g., human A549, rat ATII0) has been recorded using cell-surface biotinylation of proteins followed by pulldown with streptavidin beads. Pump endocytosis is promoted by $\mathrm{CO}_{2}$ and by hypoxia, but also by thrombin (Vadász et al. 2005). The signals regulated this endocytic movement are only beginning to be identified, but hypercapnia activates ERK (extracellular signal-regulating kinase) and inhibiting ERK reduces pump endocytosis (Welch et al. 2010). On the other hand, hypoxia increases CaMKK- $\beta$ (calcium/ calmodulin-dependent protein kinase kinase 2) and ROS (reactive oxygen species), which activate AMPK (Vadász et al. 2008). Indeed, inhibiting either one of these inputs reduces hypoxia-induced pump endocytosis. It has been proposed that AMPK phosphorylates the atypical protein kinase $\mathrm{C}-\zeta$ on $\mathrm{Thr}-410$, activating it, and that this signaling pathway leads to phos- phorylation of Ser- 18 on the $\alpha 1$ subunit of the $\mathrm{Na}^{+} / \mathrm{K}^{+}$pump (Gusarova et al. 2009). This is thought to lead to ubiquitylation of a lysine residue in the vicinity of Ser-18 as preamble to the pump endocytosis (Dada et al. 2007). This mechanism is partly reenacted in the kidney in response to elevated $\mathrm{Na}^{+}$in the basolateral milieu (see below).

Finally, mitochondrial ROS are generated in the course of hypoxia and these have been implicated in the endocytic regulation of the pump (Vadász et al. 2005), apparently through phosphorylation of the AP2 adaptin $\mu 2$ subunit. The responsible kinase remains to be identified, although AAK1 (adaptor-associated protein kinase 1) has been suggested (Chen et al. 2006).

\section{$\mathrm{Na}^{+} / \mathrm{K}^{+}$-Pump Endocytosis Triggered by $\mathrm{Na}^{+}$, Dopamine, and Cardiotonic Steroids in the Kidney}

In the proximal tubule of the kidney, the $\mathrm{Na}^{+} /$ $\mathrm{K}^{+}$pump is the driving force for $\mathrm{Na}^{+}$and fluid recovery from lumen to blood $\left(\mathrm{Na}^{+}\right.$resorption). The kidney expresses the $\alpha 1$ - and $\beta 1$-subunit isoforms that are abundant at the basolateral membrane, from where the dimer is endocytosed in response to several stimuli (Bertorello and Sznajder 2005).

The presence of elevated $\mathrm{Na}^{+}$in the blood and therefore at the peritubular interstitium of the proximal tubule demands a reduction in $\mathrm{Na}^{+}$resorption from the lumen. High levels of $\mathrm{Na}^{+}$cause release of dopamine, a natriuretic hormone that increases $\mathrm{Na}^{+}$excretion by diminishing its reabsorption, primarily in the proximal tubule. Dopamine is synthesized within the kidney from L-dopa, and both local and circulating dopamine binds and activates DA1 and DA2 receptors that generate cyclic AMP. Dopamine triggers $\mathrm{Na}^{+} / \mathrm{K}^{+}$-pump endocytosis at the basolateral membrane of kidney epithelial cells through three coincident events, documented in OK (opossum kidney) cells (Chibalin et al. 1999) and renal proximal tubule cells (Pedemonte et al. 2005):

1. Phosphorylation of Ser-18 on the $\alpha 1$ subunit of the $\mathrm{Na}^{+} / \mathrm{K}^{+}$pump (Pedemonte et al. 
2005), mediated by protein kinase C- $\zeta$. This promotes association of dynamin-2 with the $\alpha$ subunit (Efendiev et al. 2002). Presumably, phosphorylation of dynamin-2 at position S848 limits basal $\mathrm{Na}^{+} / \mathrm{K}^{+}$-pump endocytosis and dopamine-regulated PP2 dephosphorylation of dynamin-2 S848 promotes $\mathrm{Na}^{+} / \mathrm{K}^{+}$-pump internalization (Efendiev et al. 2002).

2. Simultaneously, the $\alpha 1$ subunit is also phosphorylated on Y537, promoting binding of the p85 subunit of phosphatidylinositol-3kinase (PI3K). Both phosphorylation events of $\alpha 1$ on Ser-18 and Y537 are required for its endocytosis (Doné et al. 2002). Binding of $\mathrm{PI} 3 \mathrm{~K}$ to the pump occurs via interaction of the $\mathrm{SH} 3$ domain of $\mathrm{p} 85$ with a proline-rich domain of the $\alpha 1$ subunit, a region of the pump distinct from that bound by AP2 (Yudowski et al. 2000). In fact, PI3K activity enhances association of AP2 with the $\alpha 1$ subunit (Yudowski et al. 2000). This results in formation of a complex of the $\mathrm{Na}^{+} / \mathrm{K}^{+}$ pump, AP2, clathrin, and dynamin-2 (Pedemonte et al. 2005).

3. Finally, the adaptin $\mu 2$ subunit is phosphorylated on T156 in response to dopamine and ROS (Chen et al. 2006), and $\mu 2$ binds directly to the YLEL motif on the main cytoplasmic loop of the $\mathrm{Na}^{+} / \mathrm{K}^{+}$pump (Doné et al. 2002; Chen et al. 2006). The pump then apparently internalizes all the way to late endosomes (based on subcellular fractionation experiments) from whence it can recycle to the membrane (Chibalin et al. 1999).

In addition to this interesting model, other elements contribute to pump endocytosis in epithelial cells following activation of G-protein-coupled receptors (GPCRs) by dopamine, vasopressin, or adrenergic hormones. In COS cells (a monkey kidney cell line), $\mathrm{Na}^{+} / \mathrm{K}^{+}$pump endocytosis involves its direct phosphorylation through GPCR-associated kinases 2 and 3 and binding of arrestin 2 and 3 (Kimura et al. 2007). In MDCK (Madin-Darby canine kidney) epithelial cells, inhibition of AMPK contributes to $\mathrm{Na}^{+} / \mathrm{K}^{+}$-pump endocytosis, through sparing phosphorylation of the RabGAP AS160 (thereby maintaining it in its GAP-active form) (Alves et al. 2010). This suggests that AS160, known to retain GLUT4 in intracellular stores, also retains the pump intracellularly, effectively preventing it from recycling to the cell surface.

Finally, additional to the $\mathrm{Na}^{+}$-dependent release of dopamine that regulates the pump through GPCRs, basolateral $\mathrm{Na}^{+}$appears to cause release of cardiotonic steroids (endogenous, digitalis-like factors), which act on the proximal tubule cells, sending signals that promote $\mathrm{Na}^{+} / \mathrm{K}^{+}$-pump endocytosis (Bagrov et al. 2009). In cell cultures, these endogenous cardiotonic steroids are emulated by using ouabain (irrespective of its inhibitory action on pump activity). The ouabain-induced $\mathrm{Na}^{+} /$ $\mathrm{K}^{+}$-pump endocytosis requires clathrin (Liu et al. 2004) although the same group also reported endocytosis through a cholesterol- and caveolin-1-dependent route (Liu et al. 2005). Clearly, more work is required to elucidate the endocytic route involved in the response to ouabain and, if more than one, it is paramount to identify which one is regulated, and how. Additional regulatory factors act on the pump, such as prostaglandins, reduce $\mathrm{Na}^{+} / \mathrm{K}^{+}$-pump activity in the collecting renal tubular cells, and it will be important to find if this effect is also mediated by pump endocytosis.

Collectively, the above examples illustrate the variety of stimuli that induce $\mathrm{Na}^{+} / \mathrm{K}^{+}$pump endocytosis and the diverse intracellular mechanism that participate in this phenomenon.

\section{RECIPROCAL REGULATION \\ OF METABOLISM, ENDOCYTOSIS, AND RECEPTOR SIGNALING}

Hormones and growth factors that are recognized by surface receptors have evolved mechanisms to signal differentially from the plasma membrane and endocytic locales (see Di Fiore and von Zastrow 2014). This applies particularly to receptor tyrosine kinases (RTKs) and GPCRs that impact on protein, lipid, and carbohydrate metabolism. Endocytosis is also a 
C.N. Antonescu et al.

mechanism to end defined signal transmission. Internalized receptors can then either recycle to the membrane or continue toward degradation. Receptor removal from the membrane, whether for recycling or degradation, can lead to ligand desensitization, whereas recycling affords resensitization. The internalization and postendocytic fate of the receptor-ligand complex governs the magnitude, duration, and specificity of receptor signaling (Sorkin and von Zastrow 2009; Kholodenko et al. 2010), and is tailored to conform to the physiological function of each hormone. Here we illustrate the endocytic regulation of metabolic signaling by the insulin, epidermal growth factor (EGF), $\beta 2$ adrenergic, and D2 dopamine receptors.

Regulation of Insulin Action by Insulin Receptor Endocytosis

Insulin, secreted by pancreatic $\beta$ cells in response to ingested glucose (Rorsman and Renström 2003), binds to insulin receptors (IR) present on its main metabolic target tissues (liver, fat, muscle) as well as on epithelial, endothelial, and neuronal cells. Insulin binding to IR activates mitogenic signaling (e.g., Shc to Erk), gene expression (e.g., Foxo), and is a critical regulator of systemic carbohydrate and lipid metabolism (through Akt) (Saltiel and Kahn 2001). Insulin-dependent clearance of dietary glucose from blood involves the rapid mobilization of GLUT4 vesicles described above, which is regulated by the phosphatidylinositol-3-kinase to Akt axis that activates small $G$ proteins directing vesicle traffic (Zaid et al. 2008; Foley et al. 2011).

Upon binding insulin, the IR rapidly internalizes via CME in rat liver cells (Pilch et al. 1983), 3T3-L1 adipocytes (Fan et al. 1982), mouse embryonic fibroblasts (Morcavallo et al. 2012), and CHO cells (Paccaud et al. 1992; Carpentier et al. 1993), as well as through nonclathrin mechanism(s) in rat adipocytes (Gustavsson et al. 1999; Fagerholm et al. 2009), endothelial cells (Wang et al. 2011), and mouse embryonic fibroblasts (Morcavallo et al. 2012). IR endocytosis is required for (1) transendothelial insulin transfer, (2) mitogenic and meta- bolic signaling, and (3) insulin degradation to terminate its action.

\section{IR Endocytosis in Transendothelial Insulin Transport}

Transendothelial insulin transport may represent the rate-limiting step of insulin action in vivo (Miles et al. 1995; Barrett et al. 2009), and in aorta endothelial cells occurs through a saturable mechanism involving caveolar internalization of insulin-IR complexes (Barrett et al. 2011). IR internalization and effective insulin transcytosis in endothelial cells determines insulin availability to muscle and fat cells. Surprisingly, the molecular underpinnings of this transendothelial transfer remain obscure, possibly due to suitable microvascular endothelial cell systems.

\section{IR Endocytosis Controls Mitogenic but Not Metabolic Signaling}

IR endocytosis is slow in skeletal muscle and fat cells, but fast in the liver. Upon internalization and dissociation from insulin in endosomes, the IR retains tyrosine kinase activity (Rosen et al. 1983; Klein et al. 1987) and activated insulin signaling intermediates are associated with endosomes in Fao hepatoma and rat liver cells (Backer et al. 1989; Balbis et al. 2000), adipocytes (Kublaoui et al. 1995), and skeletal muscle (Dombrowski et al. 2000). Interestingly, blocking IR internalization impairs insulin-stimulated Shc and Erk (but not Akt) phosphorylation in hepatoma and CHO cells (Ceresa et al. 1998; Hamer et al. 2002) but not in 3T3-L1 adipocytes (Kao et al. 1998). These findings suggest that IR endocytosis is required for activation of MAPK in a cell-selective manner, but is not required for Akt activation. In fact, inhibiting IR endocytosis does not prevent the Akt-dependent GLUT4 translocation, stimulation of glucose transport, or glycogen synthesis in adipocytes (Ceresa et al. 1998; Kao et al. 1998). Consistent with these differential requirements for IR endocytosis of the mitogenic versus metabolic facets insulin signaling, the Erk-dependent transcription of $c$-fos but not the Akt-dependent regulation of 
the glucokinase gene by insulin was blocked by inhibition of IR endocytosis in INS1 cells (Uhles et al. 2007). Hence, the Akt-dependent metabolic facets of IR signaling do not require receptor endocytosis; however, IR endocytosis may provide negative-feedback regulation (Brännmark et al. 2010).

\section{IR Internalization Leading to Insulin Degradation}

Up to $50 \%$ of insulin secreted into the portal circulation is first degraded by the liver, a process that requires insulin binding to IR, receptor internalization, and insulin degradation in endosomes (Valera Mora et al. 2003). Once insulin reaches the peripheral circulation, its levels are again controlled by uptake and degradation in liver, in addition to regulation of insulin levels by uptake in the kidney, muscle, and fat (Valera Mora et al. 2003). IR endocytosis in the liver requires the cardioembryonic antigen-related cell adhesion molecule 1 (CEACAM1) (Poy et al. 2002), whereas in the kidney, insulin binds to megalin, and insulin-megalin complexes internalize via clathrin endocytosis that proceeds to lysosomal insulin degradation (Orlando et al. 1998). In all instances, including muscle and adipose cells, insulin dissociates from the IR in endosomes (Carpentier et al. 1986) and is rapidly degraded in by endosomal insulin-degrading enzymes (Fig. 4) (Doherty et al. 1990; Tundo et al. 2013). The IR is not degraded and is instead rapidly recycled to the membrane (Carpentier et al. 1986; Knutson 1991).

\section{Inefficient Ligand-Stimulated IR Degradation}

Compared with the IR, the EGF receptor (EGFR) is more efficiently degraded upon ligand binding and internalization. EGF stimulation activates several prosurvival and mitogenic signaling pathways (Huang et al. 2007). EGF remains bound to EGFR during endosomal transit, and this is required to cause EGFR ubiquitination leading to its lysosomal degradation (Acconcia et al. 2009), although some EGFR recycling also occurs (Fig. 4) (Sorkin and Goh

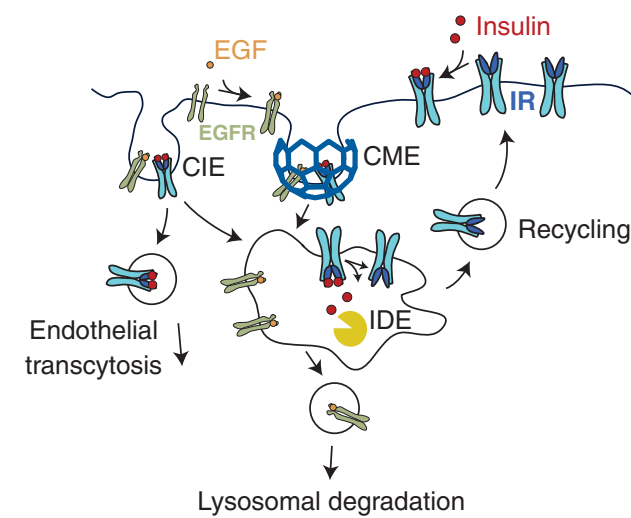

Figure 4. The internalization and recycling of the insulin receptor. Insulin binding to its receptor (IR) results in rapid internalization of the insulin-IR complex via either clathrin-mediated endocytosis (CME) or clathrin-independent endocytosis (CIE). On arrival within the acidic environment of endosomes, insulin dissociates from the IR. Insulin is degraded by insulin-degrading enzymes (IDE), whereas the IR undergoes efficient recycling to the PM. In contrast to other tissues, in endothelial cells insulin predominantly undergoes transcytosis without degradation. By comparison, the binding of epidermal growth factor (EGF) to its receptor (EGFR) results in rapid internalization leading largely to lysosomal degradation of the EGF-EGFR complex.

2009). Down-regulation of EGFR provides a limit to the duration of mitogenic signaling.

Although the IR can undergo ubiquitination under some circumstances, this does not result in significant IR degradation (Kishi et al. 2007; Song et al. 2013). Insulin dissociation in endosomes is critical for IR recycling, as mutations of K460 in IR that impair insulin-IR endosomal dissociation lead to IR degradation and insulin resistance in vivo (Kadowaki et al. 1990). That the IR is rapidly recycled and not efficiently degraded ensures that insulin action is controlled by systemic insulin availability and not peripheral tissue IR down-regulation.

Hence, EGFR and IR differ in the extent to which RTK ubiquitination controls the endomembrane itinerary of the receptor. In addition to receptor ubiquitination by receptor-proximal signaling events, RTKs may also use receptor-distal signaling to broadly control the membrane traffic of numerous other proteins. A 
C.N. Antonescu et al.

recent study in yeast found that activation of mTOR resulted in control of ubiquitin ligase targeting by arrestin-related proteins (ARTs, homologous to mammalian ARRDCs), which in turn led to ubiquitination and internalization of a diverse group of cell-surface proteins (MacGurn et al. 2011). This work raises the possibility that activation of mTOR by RTKs in mammals may lead to robust control of the endomembrane traffic and function of a large number of cellsurface transporters and receptors.

\section{Regulation of GPCR Signaling by Endocytosis}

GPCRs regulate multiple aspects of cellular and systemic metabolism. GPCR agonists stimulate exchange of GDP for GTP on specific $G_{\alpha}$ subunits of heterotrimeric $G$ proteins, activating signaling intermediates including G-proteincoupled receptor kinases (GRKs). GRKs enable binding of $\beta$-arrestins to GPCRs, which in turn down-regulate G-protein signaling and promote CME of the receptors (Shimokawa et al. 2010). Although GPCR activation of the mitogenic MAPK pathway begins at the cell surface, signaling continues within endosomes (Sorkin and von Zastrow 2009). Interestingly, adrenergic stimulation of Erk is reduced in cells with impaired $\beta 2$-adrenergic receptor ( $\beta 2$-AR) endocytosis (Daaka et al. 1998). Hence, GPCR membrane traffic and signaling are intimately related, with specific signals emanating from distinct cellular locale(s). GPCRs show individual signatures of GRK-dependent GPCR phosphorylation, $\beta$-arrestin binding, and ubiquitylation. Here, we examine the control of metabolism by endocytosis of $\beta 2-\mathrm{AR}$ and D2dopamine receptor (D2DR), which contribute to the peripheral and central regulation of metabolism, respectively.

\section{Adrenergic Control of Lipolysis Depends on $\beta 2-A R$ Endocytosis}

Agonist stimulation of $\beta 2-\mathrm{AR}$ in adipocytes causes release of fatty acids from triglyceride stores. Adrenergic stimulation elicits rapid $\beta 2$ AR CME. $\beta 2$-AR then undergoes Rab11-dependent recycling to the cell surface (Seachrist et al.
2000; Parent et al. 2009) with minimal receptor degradation (Tsao and von Zastrow 2000), although prolonged adrenergic stimulation causes $\beta 2$-AR degradation (Moore et al. 1999). Importantly, impairment of $\beta 2$-AR endocytosis by perturbation of Arf6 or dynamin selectively blunts adrenergic stimulation of lipolysis (Liu et al. 2010). Consistent with a physiological contribution of $\beta 2$-AR endocytosis to systemic metabolism, polymorphisms of $\beta 2-\mathrm{AR}$ (R16G and Q27E) with defective adrenergic desensitization (Dishy et al. 2001) are linked to differences in fat metabolism and obesity (Ukkola et al. 2000; Corbalan et al. 2002). Hence, $\beta 2$-AR endocytosis is a critical controller of lipolysis, and suggests that either multiple cycles of $\beta 2$-AR internalization and recycling or endosomal-specific $\beta 2$-AR signaling are required for stimulation of lipolysis.

\section{D2DR Endocytosis Controls Feeding and Energy Expenditure}

D2DR is highly expressed in the striatum and nucleus accumbens regions of the brain, which regulate food intake (Stice et al. 2008; Beaulieu and Gainetdinov 2011). D2DR controls behavior associated with food intake and energy expenditure (Meguid et al. 2000). D2DR undergoes rapid internalization leading to desensitization following stimulation with dopamine or other ligands (Gainetdinov et al. 2004), and this occurs via clathrin-dependent (Paspalas et al. 2006) or -independent mechanisms (Vickery and von Zastrow 1999). Agonist-stimulated internalization of D2DR is GRK- and $\beta$-arrestinindependent, and hence involves a noncanonical endocytic mechanism for receptor desensitization, although $\beta$-arrestins do contribute to D2DR signaling (Namkung et al. 2009). The adaptor protein CIN85 (Shimokawa et al. 2010) as well as the BLOC-1 complex (Iizuka et al. 2007) are required for agonist-stimulated D2DR internalization, and subsequent recycling leading to D2DR resensitization occurs via a slow Rab-11-dependent pathway (Li et al. 2012). Importantly, mice lacking neuronal CIN85 that showed defective D2DR endocytosis in the striatum were lean despite having 
elevated food intake (Shimokawa et al. 2010), suggesting that D2DR endocytosis may impact on energy expenditure (or may reflect action of other CIN85-dependent receptors). These results exemplify how endocytosis in neurons critically impacts on systemic metabolism.

\section{CONCLUDING REMARKS AND FUTURE DIRECTIONS}

We have examined how the regulated endocytosis of nutrient carriers (e.g., TfR1, LDLR), transporters (GLUTs and $\mathrm{Na} / \mathrm{K}$-ATPase), and signaling receptors (IR, $\beta 2-\mathrm{AR}, \mathrm{D} 2 \mathrm{DR})$ facilitate or limit the function of these important regulators of systemic and cellular metabolism. For many of these examples, the regulation of endocytosis is well documented, and a critical physiological role for endocytosis in the homeostasis of various nutrients is emerging. Nonetheless, there is still much to learn about the molecular mechanisms regulating carrier, transporter, and receptor endocytosis within the context of metabolic homeostasis.

Furthermore, given the diversity of membrane proteins at the cell surface involved in the cellular uptake and systemic regulation of metabolites, it is surprising that relatively little is known about how the endocytosis of most transporters and receptors controls their function. Importantly, approximately half of the 590 human kinases (protein, lipid, and carbohydrate) are required for the normal endomembrane traffic of vesicular stomatitis virus (VSV) and/or Simian virus 40 (SV40), markers of clathrin-dependent and clathrin-independent endocytosis, respectively (Pelkmans et al. 2005). Indeed some of the kinases found to regulate endomembrane traffic are metabolic enzymes, such as FN3KRP, which controls protein modification by fructosamine (Pelkmans et al. 2005). This suggests that endomembrane traffic is tightly coupled to or controlled by a cell's metabolic state, and that we have only begun to understand this regulatory process. Furthermore, that mTOR was found to exert broad effects on the cell-surface membrane traffic of numerous transporters and receptors in yeast (MacGurn et al. 2011), and the central role of
mTOR as a branched chain amino acid sensor (Tokunaga et al. 2004), suggests the existence of elaborate coordination of nutrient uptake, autophagy, and hormone signaling that we are only beginning to understand.

Future work should examine how the metabolic functions of the many cellular carriers, transporters, and receptors (e.g., lipid, nucleoside or amino acid transporters, other signaling receptors) are impacted by their endocytosis. Such information, along with a better understanding of the molecular underpinnings, will provide important insight into human metabolism and may generate novel corrective therapies for metabolic disease.

\section{ACKNOWLEDGMENTS}

C.N.A. is supported by operating grant No. 125854 from the Canadian Institutes of Health Research. A.K. is supported by Operating grant No. 3707 from the Canadian Institutes of Health Research. T.E.M. is supported by NIH RO1 DK52852.

\section{REFERENCES}

${ }^{*}$ Reference is also in this collection.

Acconcia F, Sigismund S, Polo S. 2009. Ubiquitin in trafficking: The network at work. Exp Cell Res 315: 1610-1618.

Alves DS, Farr GA, Seo-Mayer P, Caplan MJ. 2010. AS160 associates with the $\mathrm{Na}^{+}, \mathrm{K}^{+}$-ATPase and mediates the adenosine monophosphate-stimulated protein kinasedependent regulation of sodium pump surface expression. Mol Biol Cell 21: 4400-4408.

Antonescu CN, Diaz M, Femia G, Planas JV, Klip A. 2008a. Clathrin-dependent and independent endocytosis of glucose transporter 4 (GLUT4) in myoblasts: Regulation by mitochondrial uncoupling. Traffic 9: 1173-1190.

Antonescu CN, Randhawa VK, Klip A. 2008b. Dissecting GLUT4 traffic components in L6 myocytes by fluorescence-based, single-cell assays. Meth Mol Biol 457: 367378.

Antonescu CN, Foti M, Sauvonnet N, Klip A. 2009. Ready, set, internalize: Mechanisms and regulation of GLUT4 endocytosis. Biosci Rep 29: 1-11.

Backer JM, Kahn CR, White MF. 1989. Tyrosine phosphorylation of the insulin receptor during insulin-stimulated internalization in rat hepatoma cells. J Biol Chem 264: 1694-1701.

Bagrov AY, Shapiro JI, Fedorova OV. 2009. Endogenous cardiotonic steroids: Physiology, pharmacology, and novel therapeutic targets. Pharmacol Rev 61: 9-38. 
C.N. Antonescu et al.

Balbis A, Baquiran G, Bergeron JJ, Posner BI. 2000. Compartmentalization and insulin-induced translocations of insulin receptor substrates, phosphatidylinositol 3-kinase, and protein kinase B in rat liver. Endocrinology 141: 4041-4049.

Barrett EJ, Eggleston EM, Inyard AC, Wang H, Li G, Chai W, Liu Z. 2009. The vascular actions of insulin control its delivery to muscle and regulate the rate-limiting step in skeletal muscle insulin action. Diabetologia 52: 752-764.

Barrett EJ, Wang H, Upchurch CT, Liu Z. 2011. Insulin regulates its own delivery to skeletal muscle by feed-forward actions on the vasculature. Am J Phys Endo Met 301: E252-E263.

Beaulieu J-M, Gainetdinov RR. 2011. The physiology, signaling, and pharmacology of dopamine receptors. Pharmacol Rev 63: 182-217.

Benziane B, Chibalin AV. 2008. Frontiers: Skeletal muscle sodium pump regulation: A translocation paradigm. Am J Phys Endo Met 295: E553-E558.

Berenguer M, Zhang J, Bruce MC, Martinez L, Gonzalez T, Gurtovenko AA, Xu T, Marchand-Brustel Y, Govers R. 2011. Dimethyl sulfoxide enhances GLUT4 translocation through a reduction in GLUT4 endocytosis in insulinstimulated 3T3-L1 adipocytes. Biochimie 93: 697-709.

Bertorello AM, Sznajder JI. 2005. The dopamine paradox in lung and kidney epithelia: Sharing the same target but operating different signaling networks. Am J Respir Cell Mol Biol 33: 432-437.

Blodgett DM, De Zutter JK, Levine KB, Karim P, Carruthers A. 2007. Structural basis of GLUT1 inhibition by cytoplasmic ATP. J Gen Physiol 130: 157-168.

Blot V, McGraw TE. 2006. GLUT4 is internalized by a cholesterol-dependent nystatin-sensitive mechanism inhibited by insulin. EMBO J 25: 5648-5658

Bonfleur ML, Vanzela EC, Ribeiro RA, de Gabriel Dorighello G, de França Carvalho CP, Collares-Buzato CB, Carneiro EM, Boschero AC, de Oliveira HCF. 2010. Primary hypercholesterolaemia impairs glucose homeostasis and insulin secretion in low-density lipoprotein receptor knockout mice independently of high-fat diet and obesity. Biochim Biophys Acta 1801: 183-190.

Brännmark C, Palmér R, Glad ST, Cedersund G, Strålfors P. 2010. Mass and information feedbacks through receptor endocytosis govern insulin signaling as revealed using a parameter-free modeling framework. J Biol Chem 285: 20171-20179.

Brown MS, Anderson RGW, Goldstein JL. 1983. Recycling receptors: The round-trip itinerary of migrant membrane proteins. Cell 32: 663-667.

Carpentier JL, Gazzano H, Van Obberghen E, Fehlmann M, Freychet P, Orci L. 1986. Intracellular pathway followed by the insulin receptor covalently coupled to ${ }^{125} \mathrm{I}$-photoreactive insulin during internalization and recycling. J Cell Biol 102: 989-996.

Carpentier JL, Paccaud JP, Backer J, Gilbert A, Orci L, Kahn CR, Backer J. 1993. Two steps of insulin receptor internalization depend on different domains of the $\beta$-subunit. J Cell Biol 122: 1243-1252.

Cartee GD, Douen AG, Ramlal T, Klip A, Holloszy JO. 1991. Stimulation of glucose transport in skeletal muscle by hypoxia. J Appl Physiol 70: 1593-1600.
Ceresa BP, Kao AW, Santeler SR, Pessin JE. 1998. Inhibition of clathrin-mediated endocytosis selectively attenuates specific insulin receptor signal transduction pathways. Mol Cell Biol 18: 3862-3870.

Chen Z, Krmar RT, Dada L, Efendiev R, Leibiger IB, Pedemonte CH, Katz AI, Sznajder JI, Bertorello AM. 2006. Phosphorylation of adaptor protein $-2 \mu 2$ is essential for $\mathrm{Na}^{+}, \mathrm{K}^{+}$-ATPase endocytosis in response to either $\mathrm{G}$ protein-coupled receptor or reactive oxygen species. Am J Respir Cell Mol Biol 35: 127-132.

Chibalin AV, Ogimoto G, Pedemonte CH, Pressley TA, Katz AI, Féraille E, Berggren PO, Bertorello AM. 1999. Dopamine-induced endocytosis of $\mathrm{Na}^{+}, \mathrm{K}^{+}$-ATPase is initiated by phosphorylation of Ser-18 in the rat $\alpha$ subunit and is responsible for the decreased activity in epithelial cells. J Biol Chem 274: 1920-1927.

Corbalan MS, Marti A, Forga L, Martinez-Gonzalez MA, Martinez JA. 2002. The 27Glu polymorphism of the $\beta 2$-adrenergic receptor gene interacts with physical activity influencing obesity risk among female subjects. Clin Genet 61: 305-307.

Corvera S, Chawla A, Chakrabarti R, Joly M, Buxton J, Czech MP. 1994. A double leucine within the GLUT4 glucose transporter $\mathrm{COOH}$-terminal domain functions as an endocytosis signal. J Cell Biol 126: 979-989.

Czech MP, Buxton JM. 1993. Insulin action on the internalization of the GLUT4 glucose transporter in isolated rat adipocytes. J Biol Chem 268: 9187-9190.

Daaka Y, Luttrell LM, Ahn S, Rocca GJD, Ferguson SSG, Caron MG, Lefkowitz RJ. 1998. Essential role for G protein-coupled receptor endocytosis in the activation of mitogen-activated protein kinase. J Biol Chem 273: 685-688.

Dada LA, Welch LC, Zhou G, Ben-Saadon R, Ciechanover A, Sznajder JI. 2007. Phosphorylation and ubiquitination are necessary for $\mathrm{Na}, \mathrm{K}$-ATPase endocytosis during hypoxia. Cell Signal 19: 1893-1898.

Dautry-Varsat A, Ciechanover A, Lodish HF. 1983. pH and the recycling of transferrin during receptor-mediated endocytosis. Proc Natl Acad Sci 80: 2258-2262.

Davis CG, van Driel IR, Russell DW, Brown MS, Goldstein JL. 1987. The low density lipoprotein receptor. Identification of amino acids in cytoplasmic domain required for rapid endocytosis. J Biol Chem 262: 4075-4082.

Davis CG, Lehrman MA, Russell DW, Anderson RGW, Brown MS, Goldstein JL. 1986. The J. D. mutation in familial hypercholesterolemia: Amino acid substitution in cytoplasmic domain impedes internalization of LDL receptors. Cell 45: 15-24.

De Gobbi M, Roetto A, Piperno A, Mariani R, Alberti F, Papanikolaou G, Politou M, Lockitch G, Girelli D, Fargion S, et al. 2002. Natural history of juvenile haemochromatosis. Brit J Haematol 117: 973-979.

* Di Fiore PP, von Zastrow M. 2014. Endocytosis, signaling, and beyond. Cold Spring Harb Perspect Biol doi: 10.1101/ cshperspect.a016865.

Dishy V, Sofowora GG, Xie H-G, Kim RB, Byrne DW, Stein CM, Wood AJJ. 2001. The effect of common polymorphisms of the $\beta 2$-adrenergic receptor on agonist-mediated vascular desensitization. New Engl J Med 345: 1030 1035 . 
Doherty JJ II, Kay DG, Lai WH, Posner BI, Bergeron JJ. 1990. Selective degradation of insulin within rat liver endosomes. J Cell Biol 110: 35-42.

Dombrowski L, Faure R, Marette A. 2000. Sustained activation of insulin receptors internalized in GLUT4 vesicles of insulin-stimulated skeletal muscle. Diabetes 49: 1772 1782.

Doné SC, Leibiger IB, Efendiev R, Katz AI, Leibiger B, Berggren P-O, Pedemonte CH, Bertorello AM. 2002. Tyrosine 537 within the $\mathrm{Na}^{+}, \mathrm{K}^{+}$-ATPase $\alpha$-subunit is essential for AP-2 binding and clathrin-dependent endocytosis. J Biol Chem 277: 17108-17111.

Donovan A, Lima CA, Pinkus JL, Pinkus GS, Zon LI, Robine S, Andrews NC. 2005. The iron exporter ferroportin/ Slc40al is essential for iron homeostasis. Cell Met 1: 191-200.

Douen AG, Ramlal T, Rastogi S, Bilan PJ, Cartee GD, Vranic M, Holloszy JO, Klip A. 1990. Exercise induces recruitment of the "insulin-responsive glucose transporter." Evidence for distinct intracellular insulin- and exercise-recruitable transporter pools in skeletal muscle. J Biol Chem 265: 13427-13430.

Efendiev R, Yudowski GA, Zwiller J, Leibiger B, Katz AI, Berggren P-O, Pedemonte $\mathrm{CH}$, Leibiger IB, Bertorello AM. 2002. Relevance of dopamine signals anchoring dynamin-2 to the plasma membrane during $\mathrm{Na}^{+}, \mathrm{K}^{+}$-ATPase endocytosis. J Biol Chem 277: 44108-44114.

Ewart HS, Klip A. 1995. Hormonal regulation of the $\mathrm{Na}^{+}-$ $\mathrm{K}^{+}$-ATPase: Mechanisms underlying rapid and sustained changes in pump activity. Am J Physiol 269: C295-C311.

Fagerholm S, Örtegren U, Karlsson M, Ruishalme I, Strålfors P. 2009. Rapid insulin-dependent endocytosis of the insulin receptor by caveolae in primary adipocytes. PLoS ONE 4: e5985.

Fan JY, Carpentier JL, Gorden P, Obberghen EV, Blackett NM, Grunfeld C, Orci L. 1982. Receptor-mediated endocytosis of insulin: Role of microvilli, coated pits, and coated vesicles. Proc Natl Acad Sci 79: 7788-7791.

Fazakerley DJ, Holman GD, Marley A, James DE, Stöckli J, Coster ACF. 2010. Kinetic evidence for unique regulation of GLUT4 trafficking by insulin and AMP-activated protein kinase activators in L6 myotubes. J Biol Chem 285: 1653-1660.

Feng Y, Hartig SM, Bechill JE, Blanchard EG, Caudell E, Corey SJ. 2010. The Cdc42-interacting protein-4 (CIP4) gene knock-out mouse reveals delayed and decreased endocytosis. J Biol Chem 285: 4348-4354.

Ferrannini E, Bjorkman O, Reichard GA Jr, Pilo A, Olsson M, Wahren J, DeFronzo RA. 1985. The disposal of an oral glucose load in healthy subjects. A quantitative study. Diabetes 34: $580-588$.

Foley K, Boguslavsky S, Klip A. 2011. Endocytosis, recycling, and regulated exocytosis of glucose transporter 4. Biochemistry 50: 3048-3061.

Foster LJ, Li D, Randhawa VK, Klip A. 2001. Insulin accelerates inter-endosomal GLUT4 traffic via phosphatidylinositol 3-kinase and protein kinase B. J Biol Chem 276: 44212-44221.

Gainetdinov RR, Premont RT, Bohn LM, Lefkowitz RJ, Caron MG. 2004. Desensitization of G protein-coupled receptors and neuronal functions. Annu Rev Neurosci 27: 107-144.
Garippa RJ, Judge TW, James DE, McGraw TE. 1994. The amino terminus of GLUT4 functions as an internalization motif but not an intracellular retention signal when substituted for the transferrin receptor cytoplasmic domain. J Cell Biol 124: 705-715.

Garippa RJ, Johnson A, Park J, Petrush RL, McGraw TE. 1996. The carboxyl terminus of GLUT4 contains a serine-leucine-leucine sequence that functions as a potent internalization motif in Chinese hamster ovary cells. $J$ Biol Chem 271: 20660-20668.

Gironès N, Davis RJ. 1989. Comparison of the kinetics of cycling of the transferrin receptor in the presence or absence of bound diferric transferrin. Biochem J 264: $35-46$.

Gkouvatsos K, Papanikolaou G, Pantopoulos K. 2012. Regulation of iron transport and the role of transferrin. Biochim Biophys Acta 1820: 188-202.

Goldstein JL, Brown MS. 2009. The LDL receptor. Arterioscl Throm Vas 29: 431-438.

Goodyear LJ, Hirshman MF, Horton ES. 1991. Exercise-induced translocation of skeletal muscle glucose transporters. Am J Physiol 261: E795-E799.

Gusarova GA, Dada LA, Kelly AM, Brodie C, Witters LA, Chandel NS, Sznajder JI. 2009. $\alpha 1$-AMP-activated protein kinase regulates hypoxia-induced $\mathrm{Na}, \mathrm{K}$-ATPase endocytosis via direct phosphorylation of protein kinase Ç. Mol Cell Biol 29: 3455-3464.

Gustavsson J, Parpal S, Karlsson M, Ramsing C, Thorn H, Borg M, Lindroth M, Peterson KH, Magnusson K-E, Strålfors P. 1999. Localization of the insulin receptor in caveolae of adipocyte plasma membrane. FASEB J 13: 1961-1971.

Habtemichael EN, Brewer PD, Romenskaia I, Mastick CC. 2011. Kinetic evidence that Glut4 follows different endocytic pathways than the receptors for transferrin and $\alpha 2$ macroglobulin. J Biol Chem 286: 10115-10125.

Hamer I, Foti M, Emkey R, Cordier-Bussat M, Philippe J, De Meyts P, Maeder C, Kahn CR, Carpentier J-L. 2002. An arginine to cysteine ${ }^{252}$ mutation in insulin receptors from a patient with severe insulin resistance inhibits receptor internalisation but preserves signalling events. Diabetologia 45: 657-667.

Hartig SM, Ishikura S, Hicklen RS, Feng Y, Blanchard EG, Voelker KA, Pichot CS, Grange RW, Raphael RM, Klip A, et al. 2009. The F-BAR protein CIP4 promotes GLUT4 endocytosis through bidirectional interactions with $\mathrm{N}$ WASp and Dynamin-2. J Cell Sci 122: 2283-2291.

He G, Gupta S, Yi M, Michaely P, Hobbs HH, Cohen JC. 2002. ARH is a modular adaptor protein that interacts with the LDL receptor, Clathrin, and AP-2.J Biol Chem 277: 44044-44049.

Hobbs HH, Russell DW, Brown MS, Goldstein JL. 1990. The LDL receptor locus in familial hypercholesterolemia: Mutational analysis of a membrane protein. Annu Rev Genet 24: 133-170.

Huang S, Czech MP. 2007. The GLUT4 glucose transporter. Cell Met 5: 237-252.

Huang F, Goh LK, Sorkin A. 2007. EGF receptor ubiquitination is not necessary for its internalization. Proc Natl Acad Sci 104: 16904-16909. 
C.N. Antonescu et al.

Hundal HS, Marette A, Mitsumoto Y, Ramlal T, Blostein R, Klip A. 1992. Insulin induces translocation of the $\alpha 2$ and $\beta 1$ subunits of the $\mathrm{Na}^{+} / \mathrm{K}^{+}$-ATPase from intracellular compartments to the plasma membrane in mammalian skeletal muscle. J Biol Chem 267: 5040-5043.

Iizuka Y, Sei Y, Weinberger DR, Straub RE. 2007. Evidence that the BLOC-1 protein dysbindin modulates dopamine D2 receptor internalization and signaling but not D1 internalization. J Neurosci 27: 12390-12395.

Ishikura S, Antonescu CN, Klip A. 2010. Documenting GLUT4 exocytosis and endocytosis in muscle cell monolayers. Curr Prot Cell Biol doi: 10.1002/ 0471143030.cb1515s46.

Jedrychowski MP, Gartner CA, Gygi SP, Zhou L, Herz J, Kandror KV, Pilch PF. 2010. Proteomic analysis of GLUT4 storage vesicles reveals LRP1 to be an important vesicle component and target of insulin signaling. J Bio Chem 285: 104-114.

Jeon H, Blacklow SC. 2005. Structure and physiologic function of the low-density lipoprotein receptor. Annu Rev Biochem 74: 535-562.

Jing SQ, Spencer T, Miller K, Hopkins C, Trowbridge IS. 1990. Role of the human transferrin receptor cytoplasmic domain in endocytosis: Localization of a specific signal sequence for internalization. J Cell Biol 110: 283-294.

Kadowaki H, Kadowaki T, Cama A, Marcus-Samuels B, Rovira A, Bevins CL, Taylor SI. 1990. Mutagenesis of lysine 460 in the human insulin receptor. Effects upon receptor recycling and cooperative interactions among binding sites. J Biol Chem 265: 21285-21296.

Kan O, Baldwin SA, Whetton AD. 1994. Apoptosis is regulated by the rate of glucose transport in an interleukin 3 dependent cell line. J Exp Med 180: 917-923.

Kao AW, Ceresa BP, Santeler SR, Pessin JE. 1998. Expression of a dominant interfering dynamin mutant in 3T3L1 adipocytes inhibits GLUT4 endocytosis without affecting insulin signaling. J Biol Chem 273: 25450-25457.

Karlsson HKR, Chibalin AV, Koistinen HA, Yang J, Koumanov F, Wallberg-Henriksson H, Zierath JR, Holman GD. 2009. Kinetics of GLUT4 trafficking in rat and human skeletal muscle. Diabetes 58: 847-854.

Karylowski O, Zeigerer A, Cohen A, McGraw TE. 2004 GLUT4 is retained by an intracellular cycle of vesicle formation and fusion with endosomes. Mol Biol Cel 15: 870-882.

Kholodenko BN, Hancock JF, Kolch W. 2010. Signalling ballet in space and time. Nat Rev Mol Cell Biol 11: 414426.

Kimura T, Allen PB, Nairn AC, Caplan MJ. 2007. Arrestins and spinophilin competitively regulate $\mathrm{Na}^{+}, \mathrm{K}^{+}$-ATPase trafficking through association with a large cytoplasmic loop of the $\mathrm{Na}^{+}, \mathrm{K}^{+}$-ATPase. Mol Biol Cell 18: 4508-4518.

Kishi K, Mawatari K, Sakai-Wakamatsu K, Yuasa T, Wang M, Ogura-Sawa M, Nakaya Y, Hatakeyama S, Ebina Y. 2007. APS-mediated ubiquitination of the insulin receptor enhances its internalization, but does not induce its degradation. Endocr J 54: 77-88.

Klausner RD, Ashwell G, van Renswoude J, Harford JB, Bridges KR. 1983. Binding of apotransferrin to K562 cells: Explanation of the transferrin cycle. Proc Natl Acad Sci 80: 2263-2266.
Klein HH, Freidenberg GR, Matthaei S, Olefsky JM. 1987. Insulin receptor kinase following internalization in isolated rat adipocytes. J Biol Chem 262: 10557-10564.

Klip A, Schertzer JD, Bilan PJ, Thong F, Antonescu C. 2009. Regulation of glucose transporter 4 traffic by energy deprivation from mitochondrial compromise. Acta Physiol 196: $27-35$.

Knutson VP. 1991. Cellular trafficking and processing of the insulin receptor. FASEB J 5: 2130-2138.

Kublaoui B, Lee J, Pilch PF. 1995. Dynamics of signaling during insulin-stimulated endocytosis of its receptor in adipocytes. J Biol Chem 270: 59-65.

Lauritzen HPMM, Galbo H, Toyoda T, Goodyear LJ. 2010. Kinetics of contraction-induced GLUT4 translocation in skeletal muscle fibers from living mice. Diabetes 59: 2134-2144.

Leigh SEA, Foster AH, Whittall RA, Hubbart CS, Humphries SE. 2008. Update and analysis of the University College London low density lipoprotein receptor familial hypercholesterolemia database. Ann Hum Genet 72: 485-498.

Leto D, Saltiel AR. 2012. Regulation of glucose transport by insulin: Traffic control of GLUT4. Nat Rev Mol Cell Biol 13: $383-396$

Li D, Randhawa VK, Patel N, Hayashi M, Klip A. 2001. Hyperosmolarity reduces GLUT4 endocytosis and increases its exocytosis from a VAMP2-independent pool in 16 muscle cells. J Biol Chem 276: 22883-22891.

Li Y, Roy BD, Wang W, Zhang L, Zhang L, Sampson SB, Yang Y, Lin D-T. 2012. Identification of two functionally distinct endosomal recycling pathways for dopamine $\mathrm{D}_{2}$ receptor. J Neurosci 32: 7178-7190.

Liu J, Kesiry R, Periyasamy SM, Malhotra D, Xie Z, Shapiro JI. 2004. Ouabain induces endocytosis of plasmalemmal $\mathrm{Na} / \mathrm{K}$-ATPase in LLC-PK1 cells by a clathrin-dependent mechanism. Kidney Int 66: 227-241.

Liu J, Liang M, Liu L, Malhotra D, Xie Z, Shapiro JI. 2005. Ouabain-induced endocytosis of the plasmalemmal Na/ K-ATPase in LLC-PK1 cells requires caveolin-1. Kidney Int 67: 1844-1854.

Liu Y, Zhou D, Abumrad NA, Su X. 2010. ADP-ribosylation factor 6 modulates adrenergic stimulated lipolysis in adipocytes. Am J Physiol Cell Physiol 298: C921-C928.

MacGurn JA, Hsu P-C, Smolka MB, Emr SD. 2011. TORC1 regulates endocytosis via Npr1-mediated phosphoinhibition of a ubiquitin ligase adaptor. Cell 147: 1104-1117.

MacGurn JA, Hsu P-C, Emr SD. 2012. Ubiquitin and membrane protein turnover: From cradle to grave. Annu Rev Biochem 81: 231-259.

Martin OJ, Lee A, McGraw TE. 2006. GLUT4 distribution between the plasma membrane and the intracellular compartments is maintained by an insulin-modulated bipartite dynamic mechanism. J Biol Chem 281: 484490.

Maurer ME, Cooper JA. 2006. The adaptor protein Dab2 sorts LDL receptors into coated pits independently of AP-2 and ARH. J Cell Sci 119: 4235-4246.

McGraw TE, Maxfield FR. 1990. Human transferrin receptor internalization is partially dependent upon an aromatic amino acid on the cytoplasmic domain. Cell Regul 1: $369-377$. 
Meguid MM, Fetissov SO, Varma M, Sato T, Zhang L, Laviano A, Rossi-Fanelli F. 2000. Hypothalamic dopamine and serotonin in the regulation of food intake. Nutrition 16: $843-857$.

Mettlen M, Loerke D, Yarar D, Danuser G, Schmid SL. 2010. Cargo- and adaptor-specific mechanisms regulate clathrin-mediated endocytosis. J Cell Biol 188: 919-933.

Miles PDG, Levisetti M, Reichart D, Khoursheed M, Moossa AR, Olefsky JM. 1995. Kinetics of insulin action in vivo: Identification of rate-limiting steps. Diabetes 44: $947-$ 953.

Miranda M, Sorkin A. 2007. Regulation of receptors and transporters by ubiquitination: New insights into surprisingly similar mechanisms. Mol Interv 7: 157-167.

Moore RH, Tuffaha A, Millman EE, Dai W, Hall HS, Dickey BF, Knoll BJ. 1999. Agonist-induced sorting of human $\beta 2$-adrenergic receptors to lysosomes during downregulation. J Cell Sci 112: 329-338.

Morcavallo A, Genua M, Palummo A, Kletvikova E, Jiracek J, Brzozowski AM, Iozzo RV, Belfiore A, Morrione A. 2012. Insulin and insulin-like growth factor II differentially regulate endocytic sorting and stability of insulin receptor isoform A. J Biol Chem 287: 11422-11436.

Mueckler M, Thorens B. 2013. The SLC2 (GLUT) family of membrane transporters. Mol Aspects Med 34: 121-138.

Namkung Y, Dipace C, Javitch JA, Sibley DR. 2009. G protein-coupled receptor kinase-mediated phosphorylation regulates post-endocytic trafficking of the D2 dopamine receptor. J Biol Chem 284: 15038-15051.

Nemeth E, Tuttle MS, Powelson J, Vaughn MB, Donovan A, Ward DM, Ganz T, Kaplan J. 2004. Hepcidin regulates cellular iron efflux by binding to ferroportin and inducing its internalization. Science 306: 2090-2093.

Ohno H, Stewart J, Fournier MC, Bosshart H, Rhee I, Miyatake S, Saito T, Gallusser A, Kirchhausen T, Bonifacino JS. 1995. Interaction of tyrosine-based sorting signals with clathrin-associated proteins. Science 269: 1872-1875.

Orlando RA, Rader K, Authier F, Yamazaki H, Posner BI, Bergeron JJ, Farquhar MG. 1998. Megalin is an endocytic receptor for insulin. J Am Soc Nephrol 9: 1759-1766.

Owen DJ, Evans PR. 1998. A structural explanation for the recognition of tyrosine-based endocytotic signals. Science 282: 1327-1332.

Paccaud JP, Siddle K, Carpentier JL. 1992. Internalization of the human insulin receptor. The insulin-independent pathway. J Biol Chem 267: 13101-13106.

Parent A, Hamelin E, Germain P, Parent J-L. 2009. Rab11 regulates the recycling of the $\beta 2$-adrenergic receptor through a direct interaction. Biochem J 418: 163-172.

Parikh H, Carlsson E, Chutkow WA, Johansson LE, Storgaard H, Poulsen P, Saxena R, Ladd C, Schulze PC, Mazzini MJ, et al. 2007. TXNIP regulates peripheral glucose metabolism in humans. PLoS Med 4: e158.

Paspalas CD, Rakic P, Goldman-Rakic PS. 2006. Internalization of D2 dopamine receptors is clathrin-dependent and select to dendro-axonic appositions in primate prefrontal cortex. Eur J Neurosci 24: 1395-1403.

Pedemonte CH, Efendiev R, Bertorello AM. 2005. Inhibition of $\mathrm{Na}, \mathrm{K}$-ATPase by dopamine in proximal tubule epithelial cells. Sem Nephrol 25: 322-327.
Pelkmans L, Fava E, Grabner H, Hannus M, Habermann B, Krausz E, Zerial M. 2005. Genome-wide analysis of human kinases in clathrin- and caveolae/raft-mediated endocytosis. Nature 436: 78-86.

Pilch PF, Shia MA, Benson RJ, Fine RE. 1983. Coated vesicles participate in the receptor-mediated endocytosis of insulin. J Cell Biol 96: 133-138.

* Piper RC, Dikic I, Lukacs GL. 2014. Ubiquitin-dependent sorting in endocytosis. Cold Spring Harb Perspect Biol 6: a016808.

Poy MN, Yang Y, Rezaei K, Fernström MA, Lee AD, Kido Y, Erickson SK, Najjar SM. 2002. CEACAM1 regulates insulin clearance in liver. Nature Genet 30: 270-276.

Pryor PR, Liu SC, Clark AE, Yang J, Holman GD, Tosh D. 2000. Chronic insulin effects on insulin signalling and GLUT4 endocytosis are reversed by metformin. Biochem J 348: 83-91.

Pytowski B, Judge TW, McGraw TE. 1995. An internalization motif is created in the cytoplasmic domain of the transferrin receptor by substitution of a tyrosine at the first position of a predicted tight turn. J Biol Chem 270: 9067-9073.

Qiao B, Sugianto P, Fung E, Del-Castillo-Rueda A, MoranJimenez M-J, Ganz T, Nemeth E. 2012. Hepcidin-induced endocytosis of ferroportin is dependent on ferroportin ubiquitination. Cell Met 15: 918-924.

Rathmell JC, Farkash EA, Gao W, Thompson CB. 2001. IL-7 enhances the survival and maintains the size of naive T cells. J Immunol 167: 6869-6876.

Rorsman DP, Renström E. 2003. Insulin granule dynamics in pancreatic $\beta$ cells. Diabetologia 46: 1029-1045.

Rosen OM, Herrera R, Olowe Y, Petruzzelli LM, Cobb MH. 1983. Phosphorylation activates the insulin receptor tyrosine protein kinase. Proc Natl Acad Sci 80: 3237-3240.

Rouault TA. 2006. The role of iron regulatory proteins in mammalian iron homeostasis and disease. Nat Chem Biol 2: 406-414.

Rowland AF, Fazakerley DJ, James DE. 2011. Mapping insulin/GLUT4 circuitry. Traffic 12: 672-681.

Saltiel AR, Kahn CR. 2001. Insulin signalling and the regulation of glucose and lipid metabolism. Nature 414: 799_ 806.

Seachrist JL, Anborgh PH, Ferguson SSG. 2000. ß2adrenergic receptor internalization, endosomal sorting, and plasma membrane recycling are regulated by Rab GTPases. J Biol Chem 275: 27221-27228.

Seaman MNJ. 2008. Endosome protein sorting: Motifs and machinery. Cell Mol Life Sci 65: 2842-2858.

Shimokawa N, Haglund K, Hölter SM, Grabbe C, Kirkin V, Koibuchi N, Schultz C, Rozman J, Hoeller D, Qiu C-H, et al. 2010. CIN85 regulates dopamine receptor endocytosis and governs behaviour in mice. EMBO J 29: 2421-2432.

Song R, Peng W, Zhang Y, Lv F, Wu H-K, Guo J, Cao Y, Pi Y, Zhang X, Jin L, et al. 2013. Central role of E3 ubiquitin ligase MG53 in insulin resistance and metabolic disorders. Nature 494: 375-379.

Sorkin A, Goh LK. 2009. Endocytosis and intracellular trafficking of ErbBs. Exp Cell Res 315: 683-696.

Sorkin A, von Zastrow M. 2009. Endocytosis and signalling: Intertwining molecular networks. Nat Rev Mol Cell Biol 10: $609-622$. 
C.N. Antonescu et al.

Soutar AK, Naoumova RP, Traub LM. 2003. Genetics, clinical phenotype, and molecular cell biology of autosomal recessive hypercholesterolemia. Arterioscl Throm Vas 23: 1963-1970.

Stice E, Spoor S, Bohon C, Small DM. 2008. Relation between obesity and blunted striatal response to food is moderated by TaqIA A1 allele. Science 322: 449-452.

Stöckli J, Fazakerley DJ, James DE. 2011. GLUT4 exocytosis. J Cell Sci 124: 4147-4159.

Tachiyama R, Ishikawa D, Matsumoto M, Nakayama KI, Yoshimori T, Yokota S, Himeno M, Tanaka Y, Fujita H. 2011. Proteome of ubiquitin/MVB pathway: Possible involvement of iron-induced ubiquitylation of transferrin receptor in lysosomal degradation. Genes Cells 16: 448-66.

Tokunaga C, Yoshino K, Yonezawa K. 2004. mTOR integrates amino acid- and energy-sensing pathways. Biochem Biophys Res Commun 313: 443-446.

Traub LM. 2003. Sorting it out: AP-2 and alternate clathrin adaptors in endocytic cargo selection. J Cell Biol 163: 203-208.

* Traub LM, Bonifacino JS. 2013. Cargo recognition in clathrin-mediated endocytosis. Cold Spring Harb Perspect Biol 5: a016790.

Tsao PI, von Zastrow M. 2000. Type-specific sorting of G protein-coupled receptors after endocytosis. J Biol Chem 275: $11130-11140$.

Tundo GR, Sbardella D, Ciaccio C, Bianculli A, Orlandi A, Desimio MG, Arcuri G, Coletta M, Marini S. 2013. Insulin-degrading enzyme (IDE) a novel heat shock-like protein. J Biol Chem 288: 2281-2289.

Uhles S, Moede T, Leibiger B, Berggren P-O, Leibiger IB. 2007. Selective gene activation by spatial segregation of insulin receptor B signaling. FASEB J 21: 1609-1621.

Ukkola O, Rankinen T, Weisnagel SJ, Sun G, Pérusse L, Chagnon YC, Després J-P, Bouchard C. 2000. Interactions among the $\alpha 2-, \beta 2-$, and $\beta 3$-adrenergic receptor genes and obesity-related phenotypes in the Quebec Family Study. Metabolism 49: 1063-1070.

Vadász I, Morty RE, Olschewski A, Königshoff M, Kohstall MG, Ghofrani HA, Grimminger F, Seeger W. 2005. Thrombin impairs alveolar fluid clearance by promoting endocytosis of $\mathrm{Na}^{+}, \mathrm{K}^{+}$-ATPase. Am J Resp Cell Mol 33: 343-354.

Vadász I, Dada LA, Briva A, Trejo HE, Welch LC, Chen J, Tóth PT, Lecuona E, Witters LA, Schumacker PT, et al. 2008. AMP-activated protein kinase regulates $\mathrm{CO}_{2}$-induced alveolar epithelial dysfunction in rats and human cells by promoting $\mathrm{Na}$,K-ATPase endocytosis. J Clin Invest 118: $752-762$.

Valera Mora ME, Scarfone A, Calvani M, Greco AV, Mingrone G. 2003. Insulin clearance in obesity. J Am Coll Nutr 22: 487-493.

Velebit J, Chowdhury HH, Kreft M, Zorec R. 2011. Rosiglitazone balances insulin-induced exo- and endocytosis in single 3T3-L1 adipocytes. Mol Cell Endocrinol 333: $70-77$.
Verhey KJ, Yeh JI, Birnbaum MJ. 1995. Distinct signals in the GLUT4 glucose transporter for internalization and for targeting to an insulin-responsive compartment. J Cell Biol 130: 1071-1079.

Vickery RG, von Zastrow M. 1999. Distinct dynamin-dependent and -independent mechanisms target structurally homologous dopamine receptors to different endocytic membranes. J Cell Biol 144: 31-43.

Wang H, Wang AX, Barrett EJ. 2011. Caveolin-1 is required for vascular endothelial insulin uptake. Am J Physiol Endocrinol Metab 300: E134-E144.

Watts C. 1985. Rapid endocytosis of the transferrin receptor in the absence of bound transferrin. J Cell Biol 100: 633-637.

Welch LC, Lecuona E, Briva A, Trejo HE, Dada LA, Sznajder JI. 2010. Extracellular signal-regulated kinase (ERK) participates in the hypercapnia-induced $\mathrm{Na}, \mathrm{K}$-ATPase downregulation. FEBS Lett 584: 3985-3989.

Wieman HL, Wofford JA, Rathmell JC. 2007. Cytokine stimulation promotes glucose uptake via phosphatidylinositol-3 kinase/Akt regulation of Glut 1 activity and trafficking. Mol Biol Cell 18: 1437-1446.

Wijesekara N, Tung A, Thong F, Klip A. 2006. Muscle cell depolarization induces a gain in surface GLUT4 via reduced endocytosis independently of AMPK. Am J Physiol Endocrinol Metab 290: E1276-E1286.

Wofford JA, Wieman HL, Jacobs SR, Zhao Y, Rathmell JC. 2008. IL-7 promotes Glut1 trafficking and glucose uptake via STAT5-mediated activation of Akt to support T-cell survival. Blood 111: 2101-2111.

Wu N, Zheng B, Shaywitz A, Dagon Y, Tower C, Bellinger G, Shen C-H, Wen J, Asara J, McGraw TE, et al. 2013. AMPK-dependent degradation of TXNIP upon energy stress leads to enhanced glucose uptake via GLUT1. Mol Cell 49: 1167-1175.

Yang J, Holman GD. 2005. Insulin and contraction stimulate exocytosis, but increased AMP-activated protein kinase activity resulting from oxidative metabolism stress slows endocytosis of GLUT4 in cardiomyocytes. J Biol Chem 280: $4070-4078$.

Yang J, Holman GD. 2006. Long-term metformin treatment stimulates cardiomyocyte glucose transport through an AMP-activated protein kinase-dependent reduction in GLUT4 endocytosis. Endocrinology 147: 2728-2736.

Yudowski GA, Efendiev R, Pedemonte CH, Katz AI, Berggren PO, Bertorello AM. 2000. Phosphoinositide-3 kinase binds to a proline-rich motif in the $\mathrm{Na}^{+}, \mathrm{K}^{+}$-ATPase $\alpha$ subunit and regulates its trafficking. Proc Natl Acad Sci 97: 6556-6561.

Zaid H, Antonescu CN, Randhawa VK, Klip A. 2008. Insulin action on glucose transporters through molecular switches, tracks and tethers. Biochem J 413: 201-215.

Zhao Z, Pompey S, Dong H, Weng J, Garuti R, Michaely P. 2013. S-nitrosylation of ARH is required for LDL uptake by the LDL receptor. J Lipid Res 54: 1550-1559. 


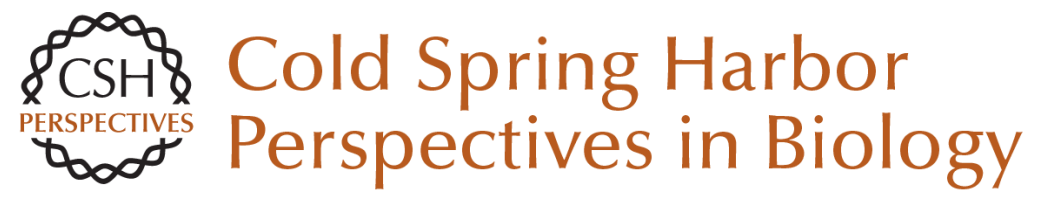

\section{Reciprocal Regulation of Endocytosis and Metabolism}

Costin N. Antonescu, Timothy E. McGraw and Amira Klip

Cold Spring Harb Perspect Biol 2014; doi: 10.1101/cshperspect.a016964

Subject Collection Endocytosis

\section{Endocytosis: Past, Present, and Future} Sandra L. Schmid, Alexander Sorkin and Marino Zerial

Rab Proteins and the Compartmentalization of the Endosomal System

Angela Wandinger-Ness and Marino Zerial

Cargo Sorting in the Endocytic Pathway: A Key Regulator of Cell Polarity and Tissue Dynamics Suzanne Eaton and Fernando Martin-Belmonte

Unconventional Functions for Clathrin, ESCRTs, and Other Endocytic Regulators in the

Cytoskeleton, Cell Cycle, Nucleus, and Beyond:

Links to Human Disease

Frances M. Brodsky, R. Thomas Sosa, Joel A. Ybe, et al.

Endocytosis of Viruses and Bacteria Pascale Cossart and Ari Helenius

Lysosomal Adaptation: How the Lysosome

Responds to External Cues Carmine Settembre and Andrea Ballabio

Reciprocal Regulation of Endocytosis and Metabolism

Costin N. Antonescu, Timothy E. McGraw and Amira Klip

Endocytosis and Autophagy: Exploitation or Cooperation?

Sharon A. Tooze, Adi Abada and Zvulun Elazar
Imaging and Modeling the Dynamics of

Clathrin-Mediated Endocytosis

Marcel Mettlen and Gaudenz Danuser

Endocytic Accessory Factors and Regulation of

Clathrin-Mediated Endocytosis

Christien J. Merrifield and Marko Kaksonen

The Complex Ultrastructure of the Endolysosomal

System Judith Klumperman and Graça Raposo

The Biogenesis of Lysosomes and

Lysosome-Related Organelles

J. Paul Luzio, Yvonne Hackmann, Nele M.G.

Dieckmann, et al.

Endocytosis, Signaling, and Beyond Pier Paolo Di Fiore and Mark von Zastrow

Clathrin-Independent Pathways of Endocytosis Satyajit Mayor, Robert G. Parton and Julie G. Donaldson

The Role of Endocytosis during Morphogenetic Signaling Marcos Gonzalez-Gaitan and Frank Jülicher

Role of Endosomes and Lysosomes in Human Disease

Frederick R. Maxfield

For additional articles in this collection, see http://cshperspectives.cshlp.org/cgi/collection/

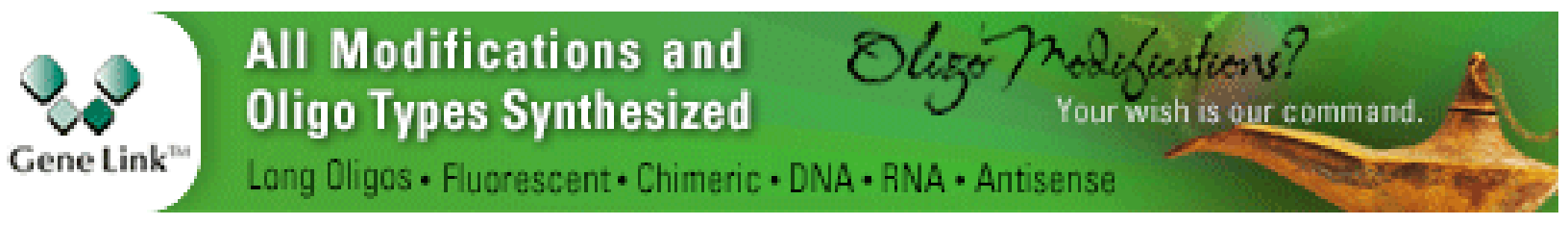


For additional articles in this collection, see http://cshperspectives.cshlp.org/cgi/collection/

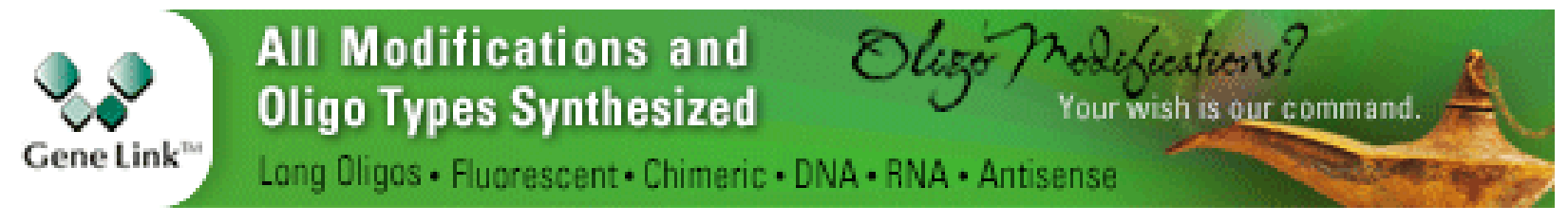

Copyright @ 2014 Cold Spring Harbor Laboratory Press; all rights reserved 